\title{
Decomposing the meridional heat transport in the climate system
}

\author{
Haijun Yang $\cdot$ Qing Li $\cdot$ Kun Wang $\cdot$ \\ Yu Sun $\cdot$ Daoxun Sun
}

Received: 17 January 2014 / Accepted: 14 October 2014 / Published online: 21 October 2014

(c) The Author(s) 2014. This article is published with open access at Springerlink.com

\begin{abstract}
The meridional heat transport (MHT) in the climate system is investigated using a state-of-the-art coupled climate model (CESM1.0). This work decomposes the MHT and studies their physics in detail. The meridional ocean heat transport (OHT) can be decomposed into the contributions from the Euler mean circulation, bolus circulation, sub-mesoscale circulation and dissipation. The Euler mean heat transport dominates the total OHT in most latitudes, except that in the Southern Ocean $\left(40-50^{\circ} \mathrm{S}\right)$ where the OHT is determined by the eddy-induced circulation and dissipation. In the Indo-Pacific the OHT is fulfilled by the wind-driven circulation, which dominates the total global OHT in the tropics. In the Atlantic the OHT is carried by both the wind-driven circulation and the thermohaline circulation, and the latter dominates the total OHT in the midhigh latitudes. The meridional atmosphere heat transport consists of the dry static energy (DSE) and latent energy (LE) transport. In the tropics the LE transport is equatorward and compensates partially the poleward DSE transport. In the extratropics, the LE and DSE are poleward and reinforce one another, both of which are dominated by the eddy components. The LE transport can be considered as the "joint air-sea mode" since the ocean controls the moisture supply. It can be also precisely obtained from the evaporation minus precipitation over the ocean and thus this work quantifies the individual ocean basin contributions to the LE transport.
\end{abstract}

H. Yang $(\bowtie) \cdot$ Q. Li $\cdot$ K. Wang $\cdot$ Y. Sun $\cdot$ D. Sun

Laboratory for Climate and Ocean-Atmosphere Studies

(LaCOAS), Department of Atmospheric and Oceanic Sciences,

School of Physics, Peking University, 209 Chengfu Road,

Beijing 100871, China

e-mail: hjyang@pku.edu.cn
Keywords Meridional heat transport . Coupled climate model - Oceanic heat transport . Atmospheric heat transport $\cdot$ Decomposition

\section{Introduction}

Assessing the meridional heat transport (MHT) in the climate system is a classical question. The atmosphere and the ocean transport heat from the equator to the poles, maintaining the stability of the Earth climate. The total MHT is usually calculated by integrating the observed net radiative fluxes, defined as the difference between the downward shortwave radiation and the outgoing longwave radiation (OLR) at the top of the atmosphere (TOA). The MHT was estimated as early as 1970s by probably the work of Vonder Haar and Oort (1973) when the satellite observation of the radiative fluxes first became available. Afterwards it has been calculated by many researchers (Oort and Vonder Haar 1976; Trenberth 1979; Masuda 1988; Carissimo et al. 1985; Savijärvi 1988; Michaud and Derome 1991; Trenberth and Solomon 1994; Trenberth and Caron 2001; Trenberth and Stepaniak 2003a, b; Wunsch 2005). One robust feature of the total MHT is that the Earth climate system is maintained by a hemispherically antisymmetric poleward heat transport with the peak value of about $5.5 \mathrm{PW}$ $\left(1 \mathrm{PW}=10^{15} \mathrm{~W}\right)$ at $35^{\circ} \mathrm{N} / \mathrm{S}$ (e.g., Trenberth and Caron 2001). Another robust feature is that the atmospheric heat transport (AHT) dominates poleward of about $30^{\circ} \mathrm{N} / \mathrm{S}$ while the oceanic heat transport (OHT) dominates in the deep tropics (Held 2001; Wunsch 2005; Czaja and Marshall 2006).

Based on the definition of heat transport, the OHT and AHT should be directly calculated from the velocity and temperature. However, for simplicity or due to lack of detailed information on the ocean and atmosphere dynamic 
and thermal structure, the OHT and AHT can be also derived from the heat flux. For example, the OHT is usually calculated from the surface net heat flux and the AHT is obtained by subtracting the OHT from the total. This is an indirect approach that is used the most extensively. This approach assumes that the change in the ocean heat storage is negligible and all net heat entering the ocean vertically through the surface has to be transported horizontally by ocean circulation. Generally these two approaches should be consistent for a steady climate. They both have weaknesses. The indirect approach cannot distinguish the heat transport by mean circulations, eddies as well as dissipation. It is also inappropriate in studying the relationship between the changes in the AHT and OHT, since they are not obtained independently. The direct calculation of the AHT and OHT is limited by the sparse observations as well as the errors or uncertainties of observations in both the atmosphere and ocean.

The consistency between the heat transports obtained from direct and indirect approaches in a coupled model system has first been examined carefully in this work, which has not been paid attention in previous studies. Then the AHT and OHT are decomposed. Every single component of the MHT is calculated directly based on the outputs from a high-resolution coupled climate model. The partitioning of the MHT in the atmosphere and ocean is the central element in describing and understanding the climate and its change (Wunsch 2005). The precise calculation of the AHT and OHT is the first step to understand their exact roles in the climate system. The OHT can be decomposed into contributions by the Euler mean circulation, mesoscale eddies, sub-mesoscale eddies and dissipation (Jayne and Marotzke 2002; Treguier et al. 2007). It can be also partitioned into the contributions from warm cells (wind-driven thermocline circulation) and cold cells (thermohaline circulation) (Ferrari and Ferreira 2011). The AHT consists of the dry static energy (DSE) transport and the latent energy (LE) transport, both of which can be further partitioned into the contributions from mean circulations and eddies' activities (Trenberth and Stepaniak 2003a, b). The LE transport can be thought as an air-sea "joint" mode because the ocean determines the water vapour.

For the OHT components, consistent with previous studies the Euler mean OHT represents the total OHT very well in most regions. One of new findings in this work is that the OHT due to mesoscale eddies and dissipation determines the poleward OHT in the Southern Hemisphere (SH) midhigh latitudes. Unlike the poleward OHT in the Northern Hemisphere $(\mathrm{NH})$ that is predominantly carried out by the Euler mean current, the poleward OHT in the SH are fulfilled by the relay of the mean current, mesoscale eddies and dissipation. For the AHT components, we emphasize that the LE transport is comparable to the DSE transport and plays the critical role in the Earth energy balance. Although the water vapour transport is two orders of magnitude smaller than total air mass transport, the water vapour is 100 times more efficient than dry air in transporting heat. This makes the atmospheric LE transport significant in the climate system. This work quantifies the individual ocean contribution to the atmospheric LE transport. The equatorward LE transport in the tropical SH occurs exclusively over the Indo-Pacific, while that in the tropical NH occurs mainly over the Atlantic. Towards the higher latitudes, the Atlantic becomes more important. This is particularly clear over the ocean north of $40^{\circ} \mathrm{N}$. Although it has a zonal extension much smaller than the Pacific, the Atlantic provides the atmosphere more water vapour in the tropics, sustaining a poleward eddy LE transport in the extratropics that is stronger than the Pacific does.

This is a benchmark work for our next step studies on the MHT variability. This work matters because the direct and precise calculation of the heat transport and its subcomponents is critical when investigates their roles in the climate system. Of course the heat transport problem is not a new problem but this work for the first time examines the heat transport components thoroughly in a fully coupled Earth system model. This paper is arranged as follows. Section 2 introduces the coupled model and experiments. Section 3 discusses the spin-up process of the model climate. Section 4 examines the mean meridional overturning circulations in both the atmosphere and ocean, and quantifies the different components in the MHT. Section 5 is the conclusion and discussion. The "Appendix" lists the detailed calculations of the MHT and its components.

\section{Model and experiments}

The model used in this study is the Community Earth System Model (CESM, version 1.0) of the National Centre for Atmospheric Research (NCAR). CESM is a fully coupled global climate model that provides state-of-the-art simulations of the Earth's past, present, and future climate states (http://www2.cesm.ucar.edu/). CESM1.0 consists of five components and one coupler: the Community Atmosphere Model (Neale et al. 2013), the Community Land Model (CLM4, Lawrence et al. 2012), the Community Ice CodE (CICE4, Hunke and Lipscomb 2008), the Parallel Ocean Program (POP2, Smith et al. 2010), the Community Ice Sheet Model (Glimmer-CISM) and CESM Coupler (CPL7). CESM1.0 has been widely used and validated by the community (http://journals.ametsoc.org/ page/CCSM4/CESM1).

The model grid employed in this study is $1.9^{\circ} \times 2.5^{\circ} \mathrm{gx} 1 \mathrm{v} 6$. The atmospheric component CAM5 has 26 levels in the vertical, with the finite volume nominal 
$1.9^{\circ} \times 2.5^{\circ}$ in the horizontal. The CAM5 is essentially a new atmospheric model with improved and more realistic formulations of radiation, boundary layer, and aerosols (Neale et al. 2013; Meehl et al. 2013). The General features of the model formulation are given by Neale et al. (2010, 2013). The CLM4 has the same horizontal resolution as CAM5. The ocean component POP2 uses the grid gx1v6 with the displaced North Pole located at the Greenland. It has $60 \mathrm{lev}$ els in the vertical. The ocean horizontal grid has a uniform $1.125^{\circ}$ spacing in the zonal direction, and non-uniform spacing in the meridional direction, which resolution is $0.27^{\circ}$ near the equator, extending to the maximum $0.65^{\circ}$ at $60^{\circ} \mathrm{N} / \mathrm{S}$ and then shrinking gradually to the poles. The model physics is described in details in Danabasoglu et al. (2012). The sea ice component CICE4 has the same horizontal grid as POP2. No flux adjustments are used in CESM1.0.

Experiment analyzed in this paper is a 1,000-year control run. The control run starts from the rest with the standard configurations (http://www.cesm.ucar.edu/experiments/ cesm1.0/). The model climate as a whole reaches quasiequilibrium after 1,000 years integration. The monthly outputs are used. In the CESM POP2, the physical transport terms are partitioned into resolved and unresolved components. The resolved component, such like Euler mean mass and heat transport, can be easily obtained using model output temperature and Euler mean velocities. The unresolved components, which results from meso-scale and submesoscale processes, are parameterized using well-recognized schemes. The meso-scale eddy transport is parameterized according to Gent and McWilliams (1990) (GM90). The eddy-induced advection coefficient varies in space and time (Danabasoglu and Marshall 2007). A variable coefficient provides a better representation of changes in eddy activity resulting from variable surface momentum forcing than a constant value (Long et al. 2013), allowing the model to more realistically capture the circulation response to changing winds, particularly in the Southern Ocean (Farneti and Gent 2011). Submeso-scale eddies is parameterized by the FFH scheme (Fox-Kemper et al. 2008, 2011), depicting the restratifying effect on the mixed layer.

This paper revisits the fundamentals of MHT in the climate system. We investigate the contributions of physical processes with different spatial-scale to the MHT. The roles of Euler mean circulation, the meso-scale eddies, the submeso-scale eddies and the dissipation in the AHT and OHT are quantified. For the ocean, the contributions of individual circulation to the total OHT are also examined in details, by introducing the so-called heat function (Ferrari and Ferreira 2011). The detailed calculation of the AHT and OHT, as well as the heat function can be found in "Appendix". In this paper we focus on the mean climate, except otherwise mentioned, the data we used are averaged over the last 300 years of the 1,000-year control run.

\section{Spin-up}

It is seen that the fast spin-up period for the CESM climate is around 200 years (Fig. 1). Thereafter, the Earth's climate as a whole reaches the quasi-equilibrium (Fig. 1c, d), although the ocean is still evolving slowly. The temperature for the upper ocean (above $200 \mathrm{~m}$ ) reaches stable state quickly in 200 years, while that for the thermocline to thermohaline water has a clear cooling trend even after 1,000 years integration (Fig. 1a). The trend is around- $(0.01-0.02)^{\circ} \mathrm{C} / 100-$ year during the last 300 years of the integration. Compared to the temperature, the salinity evolves at a much slower speed. The upper ocean $(0-1 \mathrm{~km})$ has a slightly freshening trend at about- $(0.01-0.015) \mathrm{psu} / 100$-year during the last 300 years, while the deep ocean (below $2 \mathrm{~km}$ ) has a very weak salting trend (Fig. 1b). The global ocean is getting more stable during the evolving period. The density of the upper ocean is decreasing due to the freshening, while that of the lower ocean is increasing slowly due to both the cooling and salting trends.

The Earth's climate as a whole is determined by the net radiation flux at the TOA, which reaches quasi-equilibrium in decades (Fig. 1c, black line). It is interesting to see that the variations in the net downward shortwave radiation (SW) and the net outgoing long wave radiation (LW) at the TOA tend to be in phase in most latitudes. This is particularly clear in the beginning of the spin-up. The correlation between the SW and LW is higher than 0.8 in most regions. Conceptually, an increasing in the outgoing LW corresponds to a higher surface temperature, which can result in a smaller planetary albedo (for example, less sea ice in the high latitudes), and then an increasing in the net downward SW. This compensation effect between the LW and SW at the TOA leads to a reduced variability in the net radiation flux and thus a stable mean state, suggesting that the Earth's climate as a whole tends to be contained.

The total MHT of the Earth also reaches the equilibrium much faster than its two components-the AHT and the OHT (Fig. 1d). The local balance of heat flux determines the MHT. Therefore, the adjustment timescale of MHT is also very short and well consistent with that of the net radiation flux in Fig. 1c. The OHT is calculated directly from the meridional velocity and potential temperature, while the AHT here is deduced from the difference of the net radiation flux at the TOA and the net surface heat flux over the ocean, which is not explicitly related to the ocean internal dynamics. Therefore, the AHT evolves much faster than the OHT, and there is almost no correlation between them over the first 300 years, because of remarkable change in the ocean heat storage as shown in Fig. 1a. However, the AHT and OHT do have significant negative correlation during the equilibrium stage (Fig. 1d). This will be discussed in our next work. 
(a) Temperature anomaly $\left({ }^{\circ} \mathrm{C}\right)$

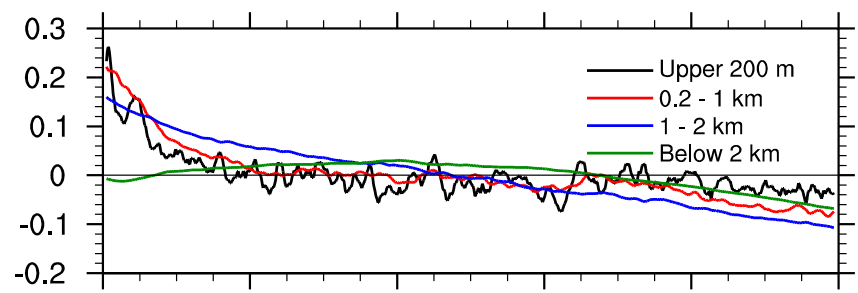

(c) Radiation flux anomaly at TOA $\left(\mathrm{W} \cdot \mathrm{m}^{-2}\right)$

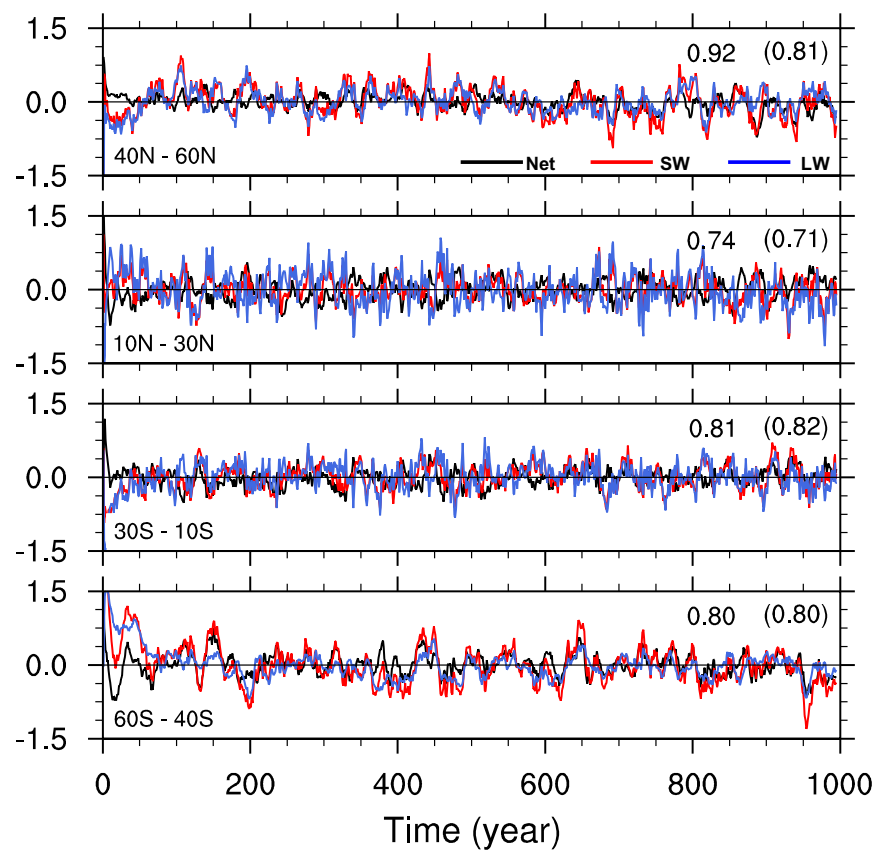

Fig. 1 Temporal evolution of global mean ocean a temperature and b salinity at different depth. The annual mean data is used. The mean values of each layer over the period of $0-1,000$ years are removed. c The net radiation flux at the TOA and $\mathbf{d}$ the meridional heat transport averaged in different latitude bands. In (c) the net downward shortwave (SW, red), net upward longwave (LW, blue) and net radiation flux (SW minus LW, black) are plotted, with their mean values over the period of $0-1,000$ years removed. The number (number in parentheses) on each panel shows the correlation between the SW

\section{Mean state}

\subsection{Ocean meridional mass streamfunction}

The ocean meridional overturning circulation (MOC) has been well established after 1,000 years integration (Fig. 2). The wind-driven subtropical cells (STC) in the upper ocean (above $500 \mathrm{~m}$ ) and the thermohaline circulation, as well as the mean thermal structure are well simulated in the CESM. Consistent with previous studies, the STC in the Pacific (Fig. 2b) shows an antisymmetric structure against the equator as a result of the symmetric surface wind forcing in the tropics. The Atlantic MOC (AMOC) consists of (b) Salinity anomaly (psu)

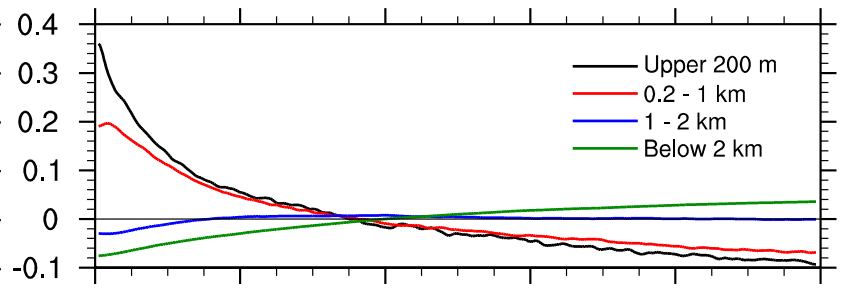

(d) Normalized MHT anomaly
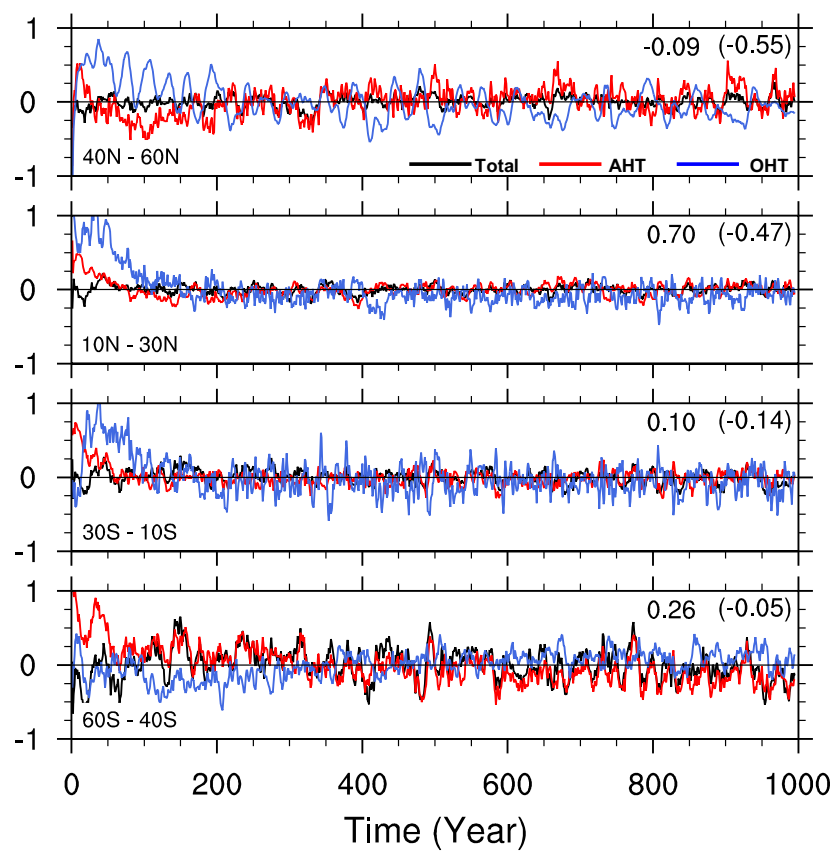

and LW over the first (last) 300 years of integration. In (d) the total meridional heat transport of the earth system (black), the AHT (red) and the OHT (blue) are calculated from the net radiation flux at the TOA, the net heat flux of the atmosphere and the oceanic velocitytemperature, respectively. The values in (d) are normalized by the 4 times of maximum of standard deviations of the total, AHT and OHT in order to easily compare. The number (number in parentheses) in (d) shows the correlation between the AHT and OHT over the first (last) 300 years. All data are applied by a 10 -year running mean

both the shallow STC and the deep thermohaline circulation (Fig. 2c). The STC is very weak and the AMOC has the maximum of $20 \mathrm{~Sv}$ that is located in the $40^{\circ} \mathrm{N}$ and at the $1,000 \mathrm{~m}$ depth. The Deacon cell in the Southern Ocean has the maximum mass transport of about $20 \mathrm{~Sv}$ that is mostly confined in the Antarctic Circumpolar Current (ACC) region and actually has little contribution to the net meridional mass and heat transport (Döös and Webb 1994). The annual mean thermal structure shows the reasonable equatorial thermocline strength and the upwelling latitudes, the subtropical shallow subduction region (Fig. 2b) as well as the deep water formation region in the North Atlantic high latitudes (Fig. 2c). 


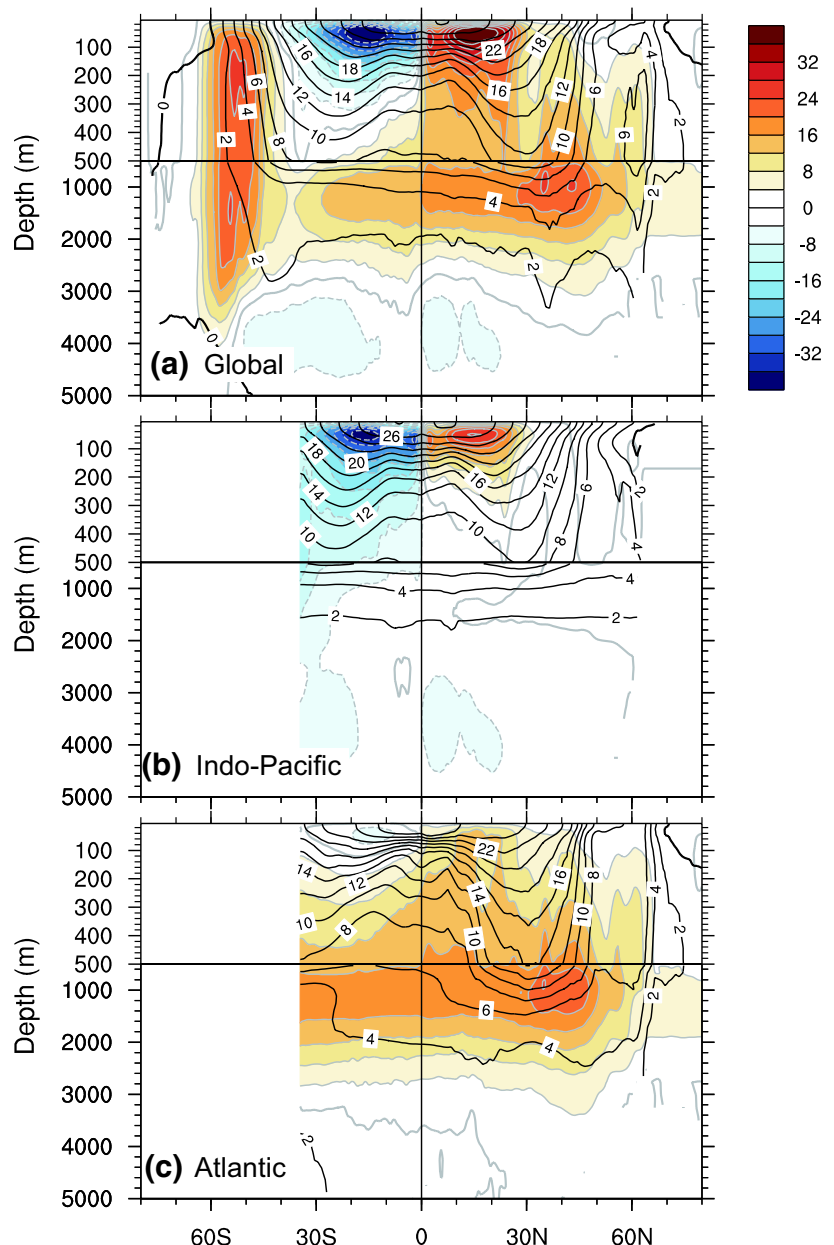

Fig. 2 The mean mass streamfunction (color shade, unit: Sv) and potential temperature (contour interval $=2{ }^{\circ} \mathrm{C}$ ) in the depth-latitude coordinate. a For the global ocean, $\mathbf{b}$ for the Indo-Pacific and $\mathbf{c}$ for the Atlantic. The color bar in (a) also works for $\mathbf{b}$ and $\mathbf{c}$

The MOC that we have "observed" (Fig. 3a) is the residual of the Euler mean circulation (Fig. $3 b$ ) and the circulations caused by meso-scale (Fig. 3c) and submesoscale eddies (Fig. 3d). Their physics have been discussed in detailed in previous studies (Marshall and Radko 2003; Fox-Kemper et al. 2008). It is seen that the strong Euler mean Deacon cell (maximum around $32 \mathrm{~Sv}$ ) can be partially balanced by the circulation associated with mesoscale eddies (about $12 \mathrm{~Sv}$, also referred as Bolus circulation) (e.g., Marshall et al. 2007), where the later is induced by the mean buoyancy gradient and parameterized by Gent-McWilliams scheme (Gent and McWilliams 1990). This term is strongest in the ACC region, in association with the strongest (weakest) meridional (vertical) buoyancy gradient (Fig. 3c). It is also visible in the NH subduction region $\left(40^{\circ} \mathrm{N}\right)$ where the meridional buoyancy gradient is also strong. The overturning circulation associated with submeso-scale eddies is mainly confined in the mixed layer (Fig. 3d), which depicts the restratifying effect on the mixed layer and is parameterized by the FFH scheme (FoxKemper et al. 2008, 2011; Fox-Kemper and Ferrari 2008). The maximum of this term can be one-fifth of the Euler mean circulation in the mixed layer. The detailed formulae can be found in the "Appendix".

The MHT is the central concern in this work. The purpose of decomposing the MOC is to identify the individual contribution of different physical processes to the MHT. For this purpose, a better way to look at the MOC is to check it in temperature coordinate, because the heat transport is eventually determined by the temperature difference between the upper northward flow and lower return flow (Held 2001). In the potential temperature-latitude space, the MOC shows the structure dramatically different from that in the depth-latitude space (Fig. 3). First of all, the warm wind-driven cells are well separated from the cold cells. Second, Deacon cell in the Southern Ocean becomes much weaker now. These features have been deliberated in many previous studies (Döös and Webb 1994; Vallis and Farneti 2009; Ferrari and Ferreira 2011; Farneti and Vallis 2013). The warm cells in both hemispheres span the temperature range from $12{ }^{\circ} \mathrm{C}$ in the mid-latitude $40-50^{\circ} \mathrm{N} /{ }^{\circ} \mathrm{S}$ to near $30{ }^{\circ} \mathrm{C}$ at the equator (Fig. 3e, f). The cold cell, that is, mostly the AMOC spans the temperature from $2{ }^{\circ} \mathrm{C}$ to $10{ }^{\circ} \mathrm{C}$, which is mainly located in the NH. The Deacon cell mostly circulates along the isopycnal layer so that the net mass transport in the temperature space is much weakened (Fig. 3f). The Bolus circulation depicts, qualitatively, the mass transport across the isopycnal layer, so that it is comparable in the depth and temperature coordinates (Fig. 3g). The submeso-scale mass transport is reduced by as much as $80 \%$ in the temperature space (Fig. $3 \mathrm{~h}$ ) because of the nearly uniform temperature in the mixed layer.

\subsection{Meridional heat transport}

The Earth's climate system is maintained by a hemispherically antisymmetric poleward heat transport with the peak value of about $5.5 \mathrm{PW}\left(1 \mathrm{PW}=10^{15} \mathrm{~W}\right)$ at $40^{\circ} \mathrm{N} / \mathrm{S}$. The AHT dominates poleward of about $30^{\circ} \mathrm{N} / \mathrm{S}$ while the OHT dominates in the deep tropics (Fig. 4). These features are well recognized and have been documented in numerous studies (e.g., Trenberth and Caron 2001; Held 2001; Wunsch 2005; Czaja and Marshall 2006). It is worth noting that previous estimate of the MHT are mostly based on the heat flux (the indirect approach we call in this work), instead of the velocity and temperature fields (direct approach) (see "Appendix" for details). In principle these two approaches should produce the same results for a steady climate. However, in practice big discrepancies usually occur in both the observations and numerical models. It is well-known that numerical models are imperfect and they have to satisfy 

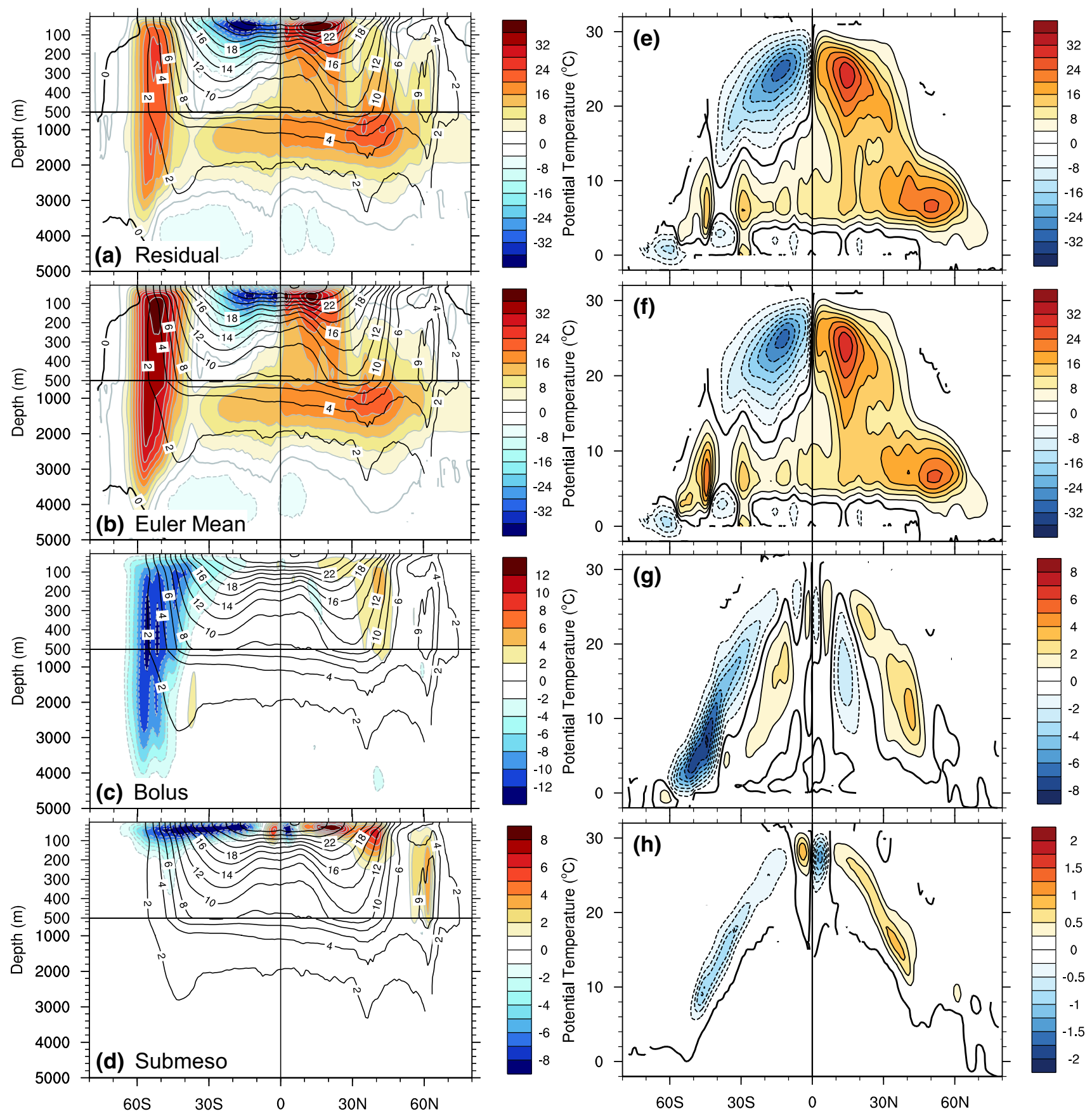

Fig. 3 The mean mass streamfunction (color, unit: Sv) in (left column) depth-latitude coordinate and (right column) potential temperature-latitude coordinate. The mean potential temperature $\left(\mathrm{CI}=2{ }^{\circ} \mathrm{C}\right)$

is superimposed on the streamfunction in the left column. The total mass streamfunction $(\mathbf{a}, \mathbf{e})$ is the residual of the Euler mean $(\mathbf{b}, \mathbf{f})$, the bolus $(\mathbf{c}, \mathbf{g})$ and the submeso-scale $(\mathbf{d}, \mathbf{h})$ components

two fundamental constraints: mass conservation and energy conservation. Violation of two constraints will certainly result in big discrepancies between these two approaches in a model system, which would cast shadow on the model's capability. Therefore, checking the consistency of the two approaches in a model climate is crucial to build the confidence on the model fundamentals.

Figure 4 shows the excellent agreement between the MHT calculated from the direct and indirect approaches. For the ocean, the $\mathrm{OHT}_{\mathrm{VT}}$ and $\mathrm{OHT}_{\mathrm{HF}}$ are completely overlapped (solid and dashed blue lines). Here the subscripts "VT" and "HF" denote the calculations directly based on velocity-potential temperature fields and indirectly from the net surface heat flux, respectively. For 


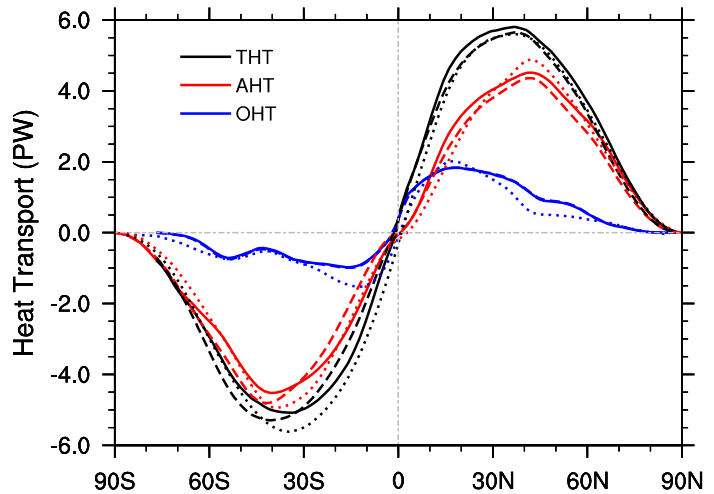

Fig. 4 The mean total meridional heat transport (THT, black), the AHT (red) and the global OHT (blue) (unit: PW). The solid lines show the heat transport calculated directly from the velocity-potential temperature fields, while the dashed lines show those deduced indirectly from the net heat flux. The dotted lines show the observations (Trenberth and Caron 2001)

the atmosphere, the difference between the $\mathrm{AHT}_{\mathrm{VT}}$ and $\mathrm{AHT}_{\mathrm{HF}}$ is very small (solid and dashed red lines), and the structures of these two are almost identical. The $\mathrm{AHT}_{\mathrm{VT}}$ is slightly bigger (smaller) than the $\mathrm{AHT}_{\mathrm{HF}}$ in most latitudes $\left(40^{\circ} \mathrm{S}-60^{\circ} \mathrm{S}\right)$. This might be due to the contributions from atmosphere dissipation and short timescale eddies. Here the $\mathrm{AHT}_{\mathrm{VT}}$ is obtained directly from the model output product of $V T$, where $V, T$ are meridional velocity and the moist potential temperature, respectively. The $\mathrm{AHT}_{\mathrm{HF}}$ is deduced from the difference of the net radiation flux at the TOA and the net surface heat flux over the ocean. The total MHT (solid and dashed black line) is the sum of OHT and AHT. The observational MHT is also plotted here for comparison (dotted lines). The modelled MHTs are well consistent with the observations.
The $\mathrm{OHT}_{\mathrm{VT}}$ can be decomposed into the contributions from Euler mean circulation $\mathrm{OHT}_{\mathrm{Eul}}$, mesoscale eddies $\mathrm{OHT}_{\mathrm{Bol}}$, submeso-scale eddies $\mathrm{OHT}_{\mathrm{Sub}}$ and dissipation $\mathrm{OHT}_{\text {Diff }}$ (Fig. 5), similar to the decomposition of the MOC as shown in Fig. 3. The sum of the first three is the total advective heat transport $\mathrm{OHT}_{\mathrm{ADV}}$. The $\mathrm{OHT}_{\mathrm{VT}}$ is the sum of advective and dissipation heat transport. First of all, for all ocean basins, the $\mathrm{OHT}_{\mathrm{VT}}$ (solid black in Fig. 5) is exactly same as the $\mathrm{OHT}_{\mathrm{HF}}$ (dashed black) as discussed before, although the deep ocean is still evolving as shown in Fig. 1a. We will show later that the heat transport by the deep ocean is very small. Second, the mixed layer eddy heat transport can be safely neglected (orange). Third, the Euler mean heat transport $\mathrm{OHT}_{\mathrm{Eul}}$ (blue) represents the $\mathrm{OHT}_{\mathrm{VT}}$ very well in most regions. However, in the Southern Ocean, both the bolus heat transport $\mathrm{OHT}_{\mathrm{Bol}}$ and dissipation heat transport $\mathrm{OHT}_{\text {Diff }}$ are significant, consistent with the sharp poleward temperature gradient. This is also studied in a ocean-alone model (Treguier et al. 2007). It is noticed that in this region, in association with the strong northward Ekman flow driven by furious westerlies, the $\mathrm{OHT}_{\mathrm{Eul}}$ is equatorward with the peak value of $0.3 \mathrm{PW}$, while the $\mathrm{OHT}_{\mathrm{Bol}}$ and $\mathrm{OHT}_{\text {Diff }}$ are southward, with the peak values of -0.3 and $-0.4 \mathrm{PW}$ respectively, reversing the $\mathrm{OHT}_{\mathrm{Eul}}$ and eventually determining the poleward heat transport. The total -0.7 PW OHT due to eddies and dissipation is well consistent with the result of Treguier et al. (2007), which gives a $-0.8 \mathrm{PW}$ eddy OHT in their ocean model. The $\mathrm{OHT}_{\text {Diff }}$ can be thought as the indirect eddy OHT (Jayne and Marotzke 2002). The total eddy effect on the OHT $\left(\mathrm{OHT}_{\mathrm{Bol}}+\mathrm{OHT}_{\mathrm{Diff}}\right)$ in the Southern Ocean in our coupled model is quantitatively consistent with Jayne and Marotzke (2002) and Treguier et al. (2007). In the 40$50^{\circ} \mathrm{N}$ of Atlantic (Fig. 5c), the $\mathrm{OHT}_{\text {Bol }}$ and $\mathrm{OHT}_{\text {Diff }}$ can be (a) Global

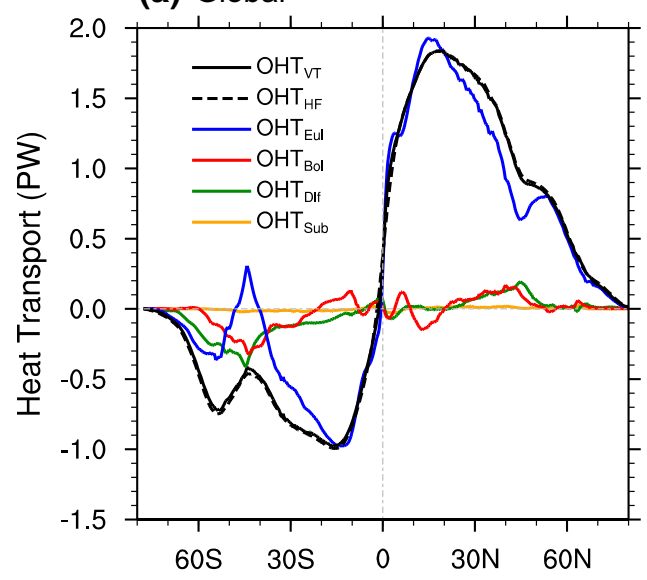

(b) Indo-Pacific

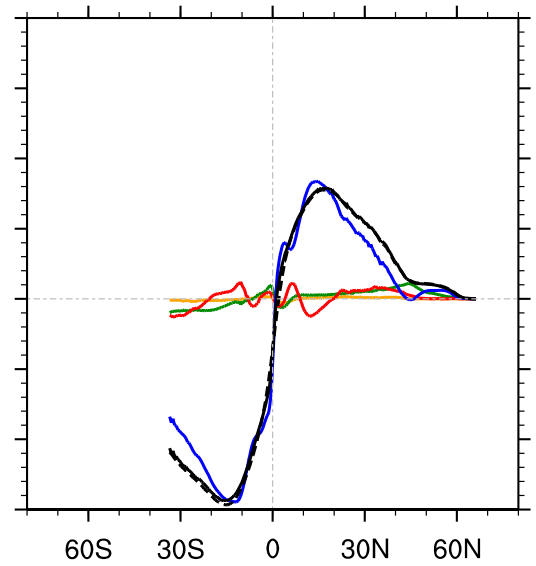

(c) Atlantic

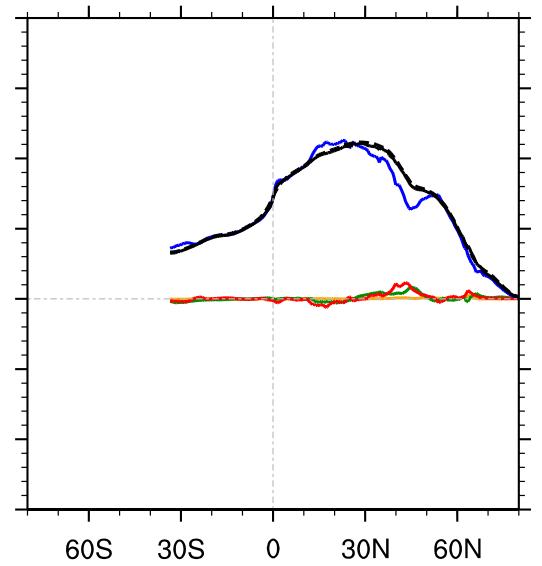

Fig. 5 The mean meridional OHT (unit: PW) for a the global ocean, b the Indo-Pacific and c the Atlantic. The total OHT (solid black) is decomposed into the contributions from the Euler mean circulation (blue), bolus (red), dissipation (green) and submeso scale eddies (orange). For comparison, the OHT deduced from the net surface heat flux is plotted as the dashed black line 
(a) Global
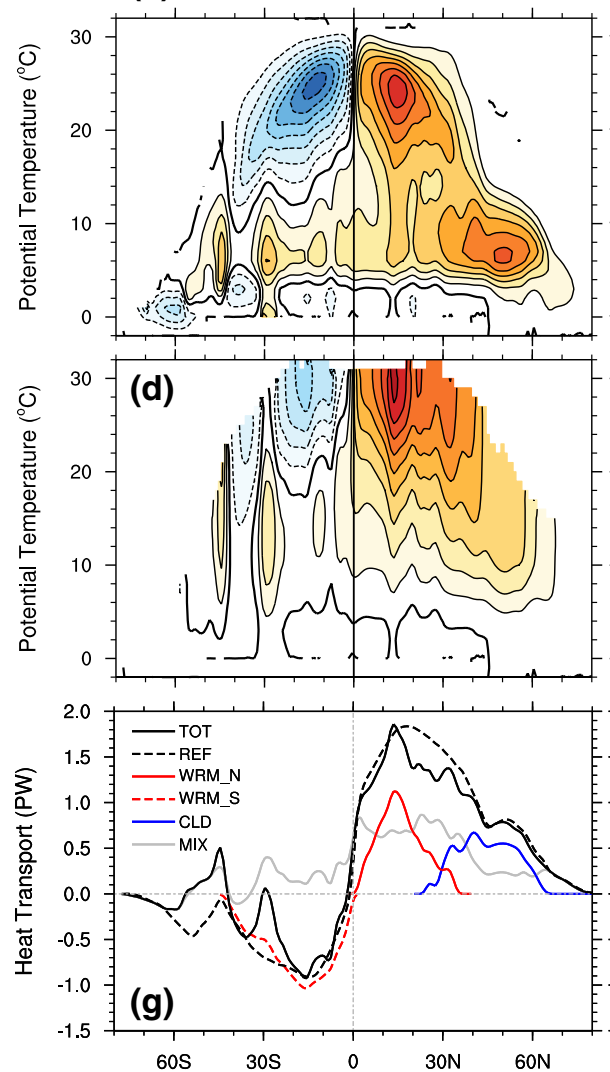

(b) Indo-Pacific
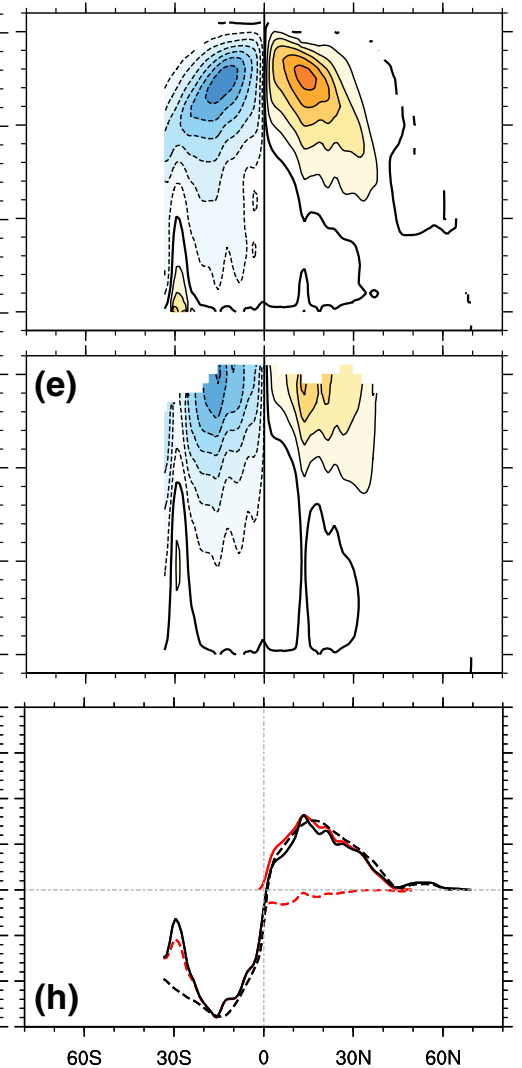

(c) Atlantic
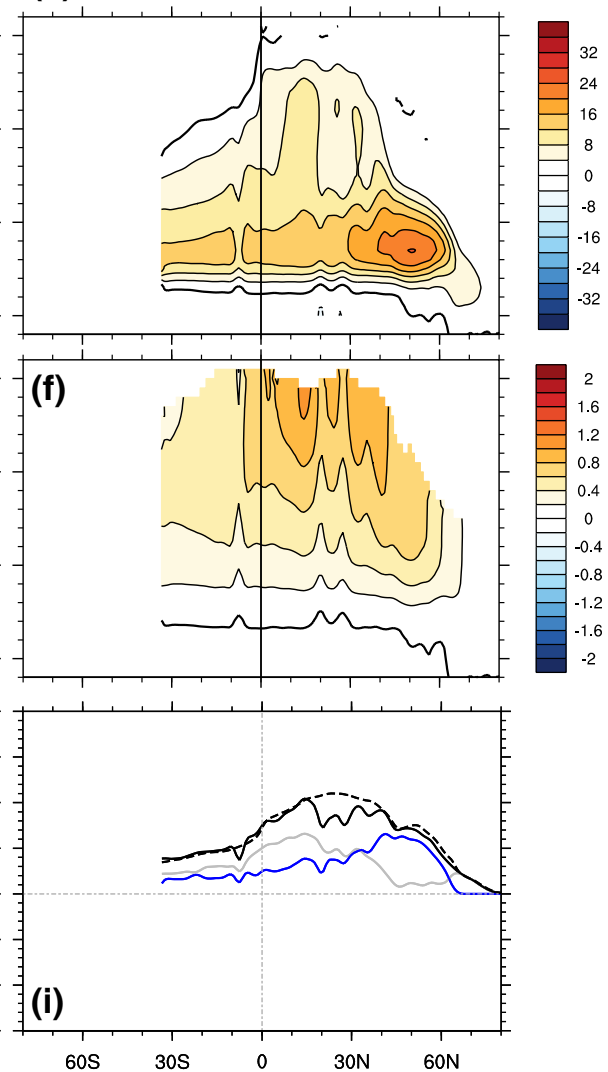

Fig. 6 (Upper panel) the mass streamfunction (unit: Sv), (middle panel) the heat function (unit: PW) in the potential temperature-latitude coordinate and (lower panel) the heat transport (unit: PW) by different cells for $(\mathbf{a}, \mathbf{d}, \mathbf{g})$ the global ocean, $(\mathbf{b}, \mathbf{e}, \mathbf{h})$ the Indo-Pacific and $(\mathbf{c}, \mathbf{f}, \mathbf{i})$ the Atlantic. The topmost value of the heat function in (d-f) equals to the total advective heat transport (solid black) in $(\mathbf{g}-\mathbf{i})$, which is further decomposed into the contributions from the shallow warm cells (red), the cold cells (blue) and the residual (or mixed) circulation (grey). The residual heat transport is obtained from the subtraction of warm and cold cell heat transport from the total advective heat transport. For comparison, the advective heat transport obtained from Fig. 5 (i.e., total minus dissipation) is plotted as the dashed black line

in the previous section which separates the ocean contribution into those by Euler mean circulation, meso-scale and submeso-scale eddies. Here we still focus on the total advective heat transport, but decomposing it into the contributions due to the shallow wind-driven circulations (warm cells), the thermohaline circulations (cold cells) and the residual (mixed) cells.

The heat function shows that the OHT are carried almost entirely by the water with temperature above $10^{\circ} \mathrm{C}$ (Fig. 6d-f). For the global ocean, the water above $10{ }^{\circ} \mathrm{C}$ represents the tropical-subtropical water above $500 \mathrm{~m}$ within $40^{\circ} \mathrm{S}-40^{\circ} \mathrm{N}$ (Fig. 2a), contributing a maximum poleward OHT of about 1.8 (1.0) PW in the NH (SH) (Fig. 6d, red lines plus grey line in Fig. $6 \mathrm{~g}$ ). The global warm cells contribute about 1.0 PW poleward heat transport, which is nearly antisymmetric to the Equator (red solid and dashed lines in Fig. 6g). The contribution from the cold cell is about 0.5 PW northward, which is mainly located in the mid-high latitudes $\mathrm{NH}\left(30-60^{\circ} \mathrm{N}\right)$ (blue line in Fig. $6 \mathrm{~g}$ ). 
The residual (mixed) circulation contributes the remaining $0.8 \mathrm{PW}$ heat transport, which is unidirectionally northward in both the hemisphere. Here we choose the $0 \mathrm{~Sv}(16 \mathrm{~Sv})$ streamlines in the $\mathrm{SH}(\mathrm{NH})$ as the separatrix of the upper ocean warm cells from the deep ocean, and the $12 \mathrm{~Sv}$ streamline as the separatrix of the cold cell from the other ocean (Fig. 6a). It is seen that the warm cell in the SH is well separated from the rest by the zero streamline, while the warm and cold cells in the $\mathrm{NH}$ is connected by the $12 \mathrm{~Sv}$ streamline to some extent. The choosing of the separatrix in the $\mathrm{NH}$ is slightly arbitrary, but it will not affect the results significantly.

To better understand the contributions of different cells to OHT, heat function in different basins is investigated. For the Indo-Pacific Ocean (Fig. 6b, e, h), the heat transport is entirely carried by the wind-driven STC. The total $\mathrm{OHT}_{\mathrm{ADV}}$ (black lines, Fig. 6h) is overlapped with the warm cells (red lines) in both hemispheres. The peak poleward heat transport in the $\mathrm{SH}$ is $50 \%$ more than that in the $\mathrm{NH}$ due to the addition of Indian Ocean. The OHT below $10{ }^{\circ} \mathrm{C}$ isothermal layer (about $400 \mathrm{~m}$ ) is too weak to mention. North of $40^{\circ} \mathrm{N}$, there is almost no net poleward advective heat transport (Fig. 6h). Here the zero streamline is chosen to outline the warm cells in both hemispheres (Fig. 6b). This also includes the deep cold cell in the southern Indian Ocean, which only accounts for less than 0.2 PW southward transport (Fig. 6e).

Different from the Indo-Pacific, in the Atlantic the heat transport is fulfilled by both the warm and cold cells (Fig. 6f) although the water mass is predominately transported by the cold cell (AMOC) (Fig. 6c). The heat function is also surface intensified, same as that in the IndoPacific. Here the $12 \mathrm{~Sv}$ streamline below $10{ }^{\circ} \mathrm{C}$ isothermal layer is chosen to isolate the cold cell from the rest circulations. The peak northward $\mathrm{OHT}_{\mathrm{ADV}}$ around $15^{\circ} \mathrm{N}$ is more than 1.0 PW, slightly bigger than that in the Pacific (black solid line in Fig. 6i). The $\mathrm{OHT}_{\mathrm{ADV}}$ in the mid-high latitudes $\mathrm{NH}$ (north of $30^{\circ} \mathrm{N}$ ) is much stronger than that in the Pacific (Fig. 6i). The AMOC transports a peak of $0.6 \mathrm{PW}$ heat northward at the $40-50^{\circ} \mathrm{N}$ (blue line in Fig. 6i). The residual circulation dominates in the tropics $\left(10^{\circ} \mathrm{S}-30^{\circ} \mathrm{N}\right)$ (grey line). The OHT by the residual circulation is carried out predominately by the surface Ekman flow (Fig. 6f). The Atlantic OHT relies on both the shallow wind-driven and deep overturning circulations. Their contributions are comparable in the South Atlantic. The warm cell surpasses the cold cell from $10^{\circ} \mathrm{S}$ to $30^{\circ} \mathrm{N}$. In the mid-high latitudes $\left(40^{\circ}-60^{\circ} \mathrm{N}\right)$, the cold cell finally dominates.

Here let us brief the contribution of warm (cold) cells in the global oceans (Fig. 7). The wind-driven warm cell in the NH Pacific accounts for 30-40\% of the total northward OHT in the tropics $\left(0-30^{\circ} \mathrm{N}\right)$ (solid red), the cold cell in the NH Atlantic accounts for $20 \%(70-80 \%)$ of the northward

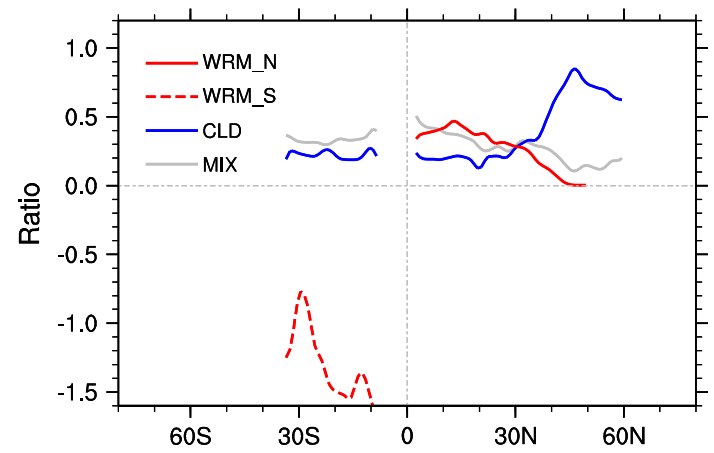

Fig. 7 Ratio of the transport by the NH Pacific warm cell (solid red), SH Pacific warm cell (dashed red), Atlantic cold cell (blue) and the mixed cell (grey) to the total advective OHT (dashed line in Fig. 6g)

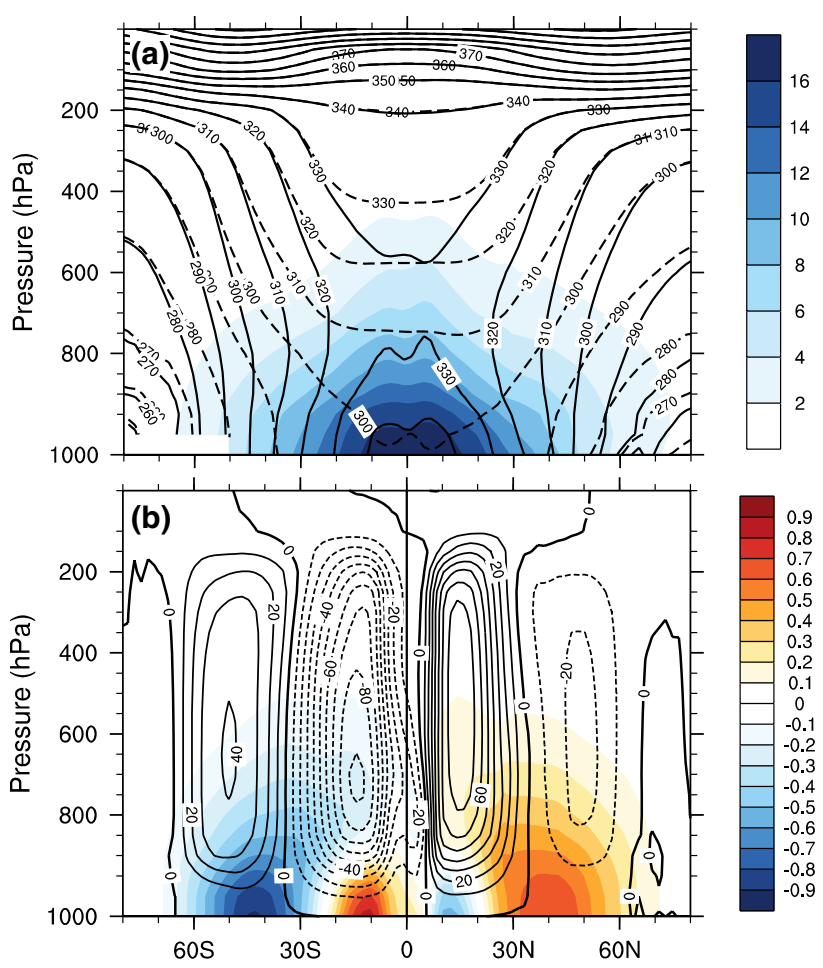

Fig. 8 a The mean moist potential temperature (dashed line, K), dry potential temperature (solid line, $\mathrm{K}$ ) and specific humidity (shade, $\mathrm{g} / \mathrm{kg}$ ). b The mean meridional mass streamfunction (contours, $10^{9} \mathrm{~kg} / \mathrm{s}$ ) and water vapour transport (shade, $\left.10^{9} \mathrm{~kg} / \mathrm{s}\right)$

OHT in the tropics (mid-high latitudes) (solid blue). The warm cell in the SH Pacific accounts for $120 \%$ of the total southward OHT (dashed red), while the cold cell in the $\mathrm{SH}$ Atlantic cancels $20 \%$ of the southward OHT (solid blue). The mixed cell in the Atlantic accounts for $30 \%$ of the northward OHT in both the hemispheres (grey line). This mixed cell contribution can be also thought as the winddriven contribution in the Atlantic. In general, in the tropics the OHT is determined by wind and carried by water above 
the depth of $500 \mathrm{~m}$. In the mid-high latitudes the OHT is carried by both the buoyancy and wind driven waters with temperature between $3-10{ }^{\circ} \mathrm{C}$, corresponding to the depth between 500 and $2,500 \mathrm{~m}$. The vast deep ocean has almost no contribution to the meridional heat transport.

\subsection{Atmosphere static energy and mass transport}

Before proceeding to discuss the AHT, let us first examine the atmosphere static energy and the mass transport. The atmosphere moist static energy (MSE), the dry static energy (DSE) and specific humidity are shown in Fig. 8a. The MSE is represented by the moist potential temperature, which includes the atmosphere internal energy, the latent energy (LE) related to the water vapour and the geopotential energy ("Atmospheric heat transport" section in Appendix). The DSE excludes the latent energy. It is seen that in the tropics (within $30^{\circ} \mathrm{N} / \mathrm{S}$ ) the MSE are nearly vertically homogeneous below $200 \mathrm{hPa}$ because of the strong water vapour latent heat release (Fig. 8a). The difference of MSE and DSE suggests the contribution of the water vapour to the tropical heating, which is over $30 \mathrm{~K}$ in the lower atmosphere (below $800 \mathrm{hPa}$ ) and $10 \mathrm{~K}$ in the upper layer (above $750 \mathrm{hPa}$ ). It is well-known that the tropical ocean provides the most water vapour to the atmosphere (Fig. 8a), which supplies the lower unit kilogram tropical atmosphere by more than $10 \mathrm{~g}$ water vapour. The water vapour effect on the potential temperature diminishes toward the high latitudes (poleward of $30^{\circ} \mathrm{N} / \mathrm{S}$ ) as well as the top of troposphere.

The mass transport and water vapour transport are shown in Fig. 8b. The mean meridional mass transport, represented mostly by the Hadley cell, is opposite to the water vapour transport in direction, with the magnitude of the former nearly 100 times of the latter. The water vapour is carried by the equatorward convergent flow in the lower troposphere, that is, the lower branch of the Hadley cell in the tropics and thus enhances the tropical convection through the latent heat releasing. It is worth noting that although the water vapour transport is two orders of magnitude smaller than total air mass transport, the water vapour is 100 times more efficient than dry air in transporting heat (Huang 2005). One kilogram of water vapour can deliver $2.5 \times 10^{6} \mathrm{~J}$ of heat (the latent heat content of water vapour $\mathrm{L}_{\mathrm{e}} \sim 2.5 \times 10^{6} \mathrm{~J} / \mathrm{kg}$ ), but one kilogram of air (water) can only release $10^{4} \mathrm{~J}\left(4.18 \times 10^{4} \mathrm{~J}\right)$ of heat for a $10^{\circ} \mathrm{C}$ cooling. This makes the atmospheric latent energy transport significant in the climate system. In Fig. 8b, the water vapour transport is directly calculated based on the model output of $v q$. In the tropics it is accomplished by the mean circulation (i.e., the Hadley cell), while in the extratropics (poleward of $25^{\circ} \mathrm{N} / \mathrm{S}$ ) it is fulfilled by the eddy activities, because the meridional velocity $v$ in the $v q$ represents mainly the Hadley cell in the tropics and then eddies in the extratropics. It is seen that the mean water vapour transport in the tropics is opposite to and also much weaker than the eddy water vapour transport in the extratropics (Fig. 8b).

\subsection{Atmospheric heat transport}

The AHT includes the contributions from dry air and water vapour (Fig. 9). The water vapour heat transport, that is, the LE transport $\left(\mathrm{AHT}_{\mathrm{LE}}\right)$ plays a critical role in the total AHT. In the deep tropics within $20^{\circ} \mathrm{N} / \mathrm{S}$, the $\mathrm{AHT}_{\mathrm{LE}}$ acts against the dry air heat transport $\mathrm{AHT}_{\mathrm{DSE}}$, reducing the heat loss towards high latitudes (Fig. 9a). Consistent with the mass transport shown in Fig. 8b, the equatorward $\mathrm{AHT}_{\mathrm{LE}}$ carried by the lower branches of the Hadley Cell converges at the latitude of Intertropical convergence zone (ITCZ) $\left(8-10^{\circ} \mathrm{N}\right)$. The $\mathrm{AHT}_{\mathrm{DSE}}$ over-compensates the $\mathrm{AHT}_{\mathrm{LE}}$ in the tropics, resulting in the poleward heat transport (Fig. 9a). It is very interesting to see that right on the Equator, the $\mathrm{AHT}_{\mathrm{DSE}}$ and $\mathrm{AHT}_{\mathrm{LE}}$ compensate with each other perfectly, leaving the zero total AHT on the Equator. This situation is different from other model studies, in which the total AHT on the Equator is required to be southward in association with the location of ITCZ at $10^{\circ} \mathrm{N}$ (Marshall et al. 2013). Here it is seen that both the maximum convergence (divergence) of $\mathrm{AHT}_{\mathrm{LE}}$ and $\mathrm{AHT}_{\mathrm{DSE}}$ are determined by the ITCZ location. In the mid-high latitudes $\left(30-60^{\circ} \mathrm{N} / \mathrm{S}\right)$ the $\mathrm{AHT}_{\mathrm{LE}}$ acts together with the $\mathrm{AHT}_{\mathrm{DSE}}$, contributing as much as one second of the total poleward AHT, particularly in the SH where the peak $\mathrm{AHT}_{\mathrm{LE}}(2 \mathrm{PW})$ is about twice of the global OHT in the same latitudes, suggesting the critical role of the water vapour in the Earth heat balance. The co-changes between the $\mathrm{AHT}_{\mathrm{LE}}$ and $\mathrm{AHT}_{\mathrm{DSE}}$ in our coupled model are in good agreement with the studies using reanalyses data (Trenberth and Stepaniak 2003a, b). Note that in Fig. 9a, we also plot the LE transport calculated from evaporation minus precipitation (EMP) over the ocean (symbolized by $\mathrm{HT}_{\mathrm{EMP}}$, dashed blue line). The $\mathrm{AHT}_{\mathrm{LE}}$ and $\mathrm{HT}_{\mathrm{EMP}}$ are perfectly matched with each other, suggesting a crucial contribution of ocean to the AHT.

The $\mathrm{AHT}_{\mathrm{DSE}}$ and $\mathrm{AHT}_{\mathrm{LE}}$ can be further decomposed into the components due to the mean circulation and eddy activities (Fig. 9b). It is well-established that the mean circulation dominates in the tropics and eddies dominates in the mid-high latitudes (Trenberth and Stepaniak 2003b). The eddy LE transport $\mathrm{AHT}_{\mathrm{ELE}}$ is always poleward. It is small and opposite to the mean LE transport $\mathrm{AHT}_{\mathrm{MLE}}$ in the tropics. The $\mathrm{AHT}_{\mathrm{ELE}}$ increases towards the higher latitude, exceeds the $\mathrm{AHT}_{\mathrm{MLE}}$ poleward of $30^{\circ} \mathrm{N} / \mathrm{S}$ and peaks at around $40-50^{\circ} \mathrm{N} / \mathrm{S}$. The $\mathrm{AHT}_{\mathrm{ELE}}$ accounts to $20 \%$ (30\%) of the total AHT in the mid-latitudes NH (SH). The eddy dry air heat transport $\mathrm{AHT}_{\mathrm{EDSE}}$ is nearly zero in the tropics and increases rapidly towards the higher latitudes, in 

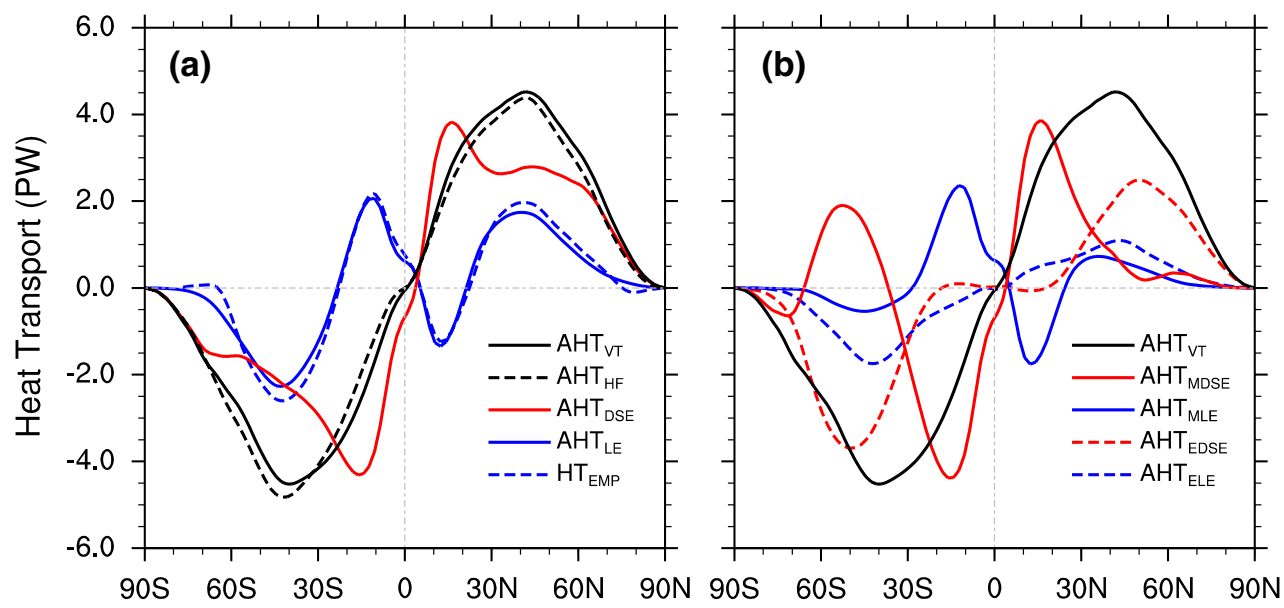

Fig. 9 The mean AHT calculated directly from the velocity and temperature (unit: $\mathrm{PW}$ ). In (a) the total $\mathrm{AHT}_{\mathrm{VT}}$ (solid black) is decomposed into the dry static energy transport $\left(\mathrm{AHT}_{\mathrm{DSE}}\right.$, red) and the $\mathrm{LE}$ transport $\left(\mathrm{AHT}_{\mathrm{LE}}\right.$, solid blue). For comparison, the $\mathrm{AHT}_{\mathrm{HF}}$ deduced from the net heat flux is plotted as the dashed black line. The latent heat transport $\left(\mathrm{HT}_{\mathrm{EMP}}\right)$ obtained from the ocean surface evaporation

accompany with the rapidly diminishing of the mean dry air heat transport $\mathrm{AHT}_{\mathrm{MDSE}}$. The $\mathrm{AHT}_{\mathrm{EDSE}}$ accounts to more than $50 \%(80 \%)$ of the total AHT in the NH (SH) mid-latitudes. It is interesting to see that in terms of heat transport, eddy activities in the $\mathrm{SH}$ is much stronger than that in the $\mathrm{NH}$, although the ocean-land contrast in the $\mathrm{NH}$ is much more significant. In the mid-high latitudes $\mathrm{SH}$, the $\mathrm{AHT}_{\text {MDSE }}$ is equatorward in association with the Ferrell Cell. This is in sharp contrast with the NH situation. It is the eddy activities in the SH that reverses the direction of $\mathrm{AHT}_{\mathrm{MDSE}}$, resulting in the nearly antisymmetric structure of the AHT. This is similar to the situation in the OHT in which the $\mathrm{OHT}_{\mathrm{Bol}}$ and $\mathrm{OHT}_{\text {Diff }}$ take control in the same latitude bands.

\subsection{Atmospheric LE transport: the "joint" mode}

The $\mathrm{AHT}_{\mathrm{LE}}$ cannot be attributed solely to the atmosphere since the water vapour in the atmosphere is predominately supplied by the ocean. It can be thought as the "joint" mode. Figure 10 shows that, excluding the land, the divergence of vertically integrated horizontal water vapour transport $(\nabla \cdot v q)$ is almost identical to the surface evaporation minus precipitation (EMP) over the global ocean. These two independent data sets give the same structure of the atmosphere water vapour divergence. Therefore, after zonal integrating on Fig. 10, the LE transport derived from the $\mathrm{EMP}\left(\mathrm{HT}_{\mathrm{EMP}}\right)$ is the same as that calculated directly from the atmosphere $v q\left(\mathrm{AHT}_{\mathrm{LE}}\right)$ as shown in Fig. 9a. The small difference between them results from the water vapour over the land, which is here proven to be trivial to the meridional AHT. The divergence of the vertically integrated horizontal minus precipitation (EMP) is also plotted as the dashed blue line. In (b) the AHT is further decomposed into transports of the mean DSE $\left(\mathrm{AHT}_{\mathrm{MDSE}}\right.$, solid red), the eddy DSE ( $\mathrm{AHT}_{\mathrm{EDSE}}$, dashed red), the mean $\mathrm{LE}\left(\mathrm{AHT}_{\mathrm{MLE}}\right.$, solid blue) and the eddy $\mathrm{LE}$ (AHT $\mathrm{ALE}_{\mathrm{EL}}$, dashed blue)

water vapour transport has once been estimated using observational data (Bryan and Oort 1984). Schmitt et al. (1989) have compared Bryan and Oort's result with their EMP observation. Over the North Atlantic these two estimations are similar to each other in the high and low latitudes but disagree greatly in midlatitudes. Our model result shows nearly identical patterns between $\nabla \cdot v q$ and EMP. Compared to the observations, however, modelled results show several discrepancies, for example, the model underestimates the evaporation in the Gulf Stream region.

Figures 9a and 10 confirm the important role of the ocean in the $\mathrm{AHT}_{\mathrm{LE}}$. The $\mathrm{AHT}_{\mathrm{LE}}$ was argued as a "coupled" mode (Huang 2005). Here we think it is better to call $\mathrm{AHT}_{\mathrm{LE}}$ the "joint" mode, because the ocean plays the role by only providing water vapour. The atmosphere provides the dynamics, determining the global precipitation pattern. The joint effect (EMP) can feed back to the ocean circulation (Goldsbrough 1933), but with the magnitudes one-two order smaller than the normal wind-driven and thermohaline circulations. In summary, the $\mathrm{AHT}_{\mathrm{LE}}$ is a joint result of atmosphere and ocean, but it is not strong enough to affect the ocean circulation significantly, which in turn is not strong enough to control the SST, the EMP and hence the latent heat flux.

$\mathrm{The}_{\mathrm{AHT}} \mathrm{LE}$ is one of the major components of the meridional heat transport of the climate system. In the extratropics (poleward of $30^{\circ} \mathrm{S} / \mathrm{N}$ ) the poleward $\mathrm{AHT}_{\mathrm{LE}}$ (Fig. 9a) is resulted from atmospheric freshwater transport from the tropics $\left(10-30^{\circ} \mathrm{S} / \mathrm{N}\right)$ to the mid-high latitudes (Fig. 10), which tends to reduce the meridional density gradient, counteracting the effect of the meridional temperature gradient on the density gradient in the upper ocean. It plays as 
(a) $\nabla \cdot(v q)$

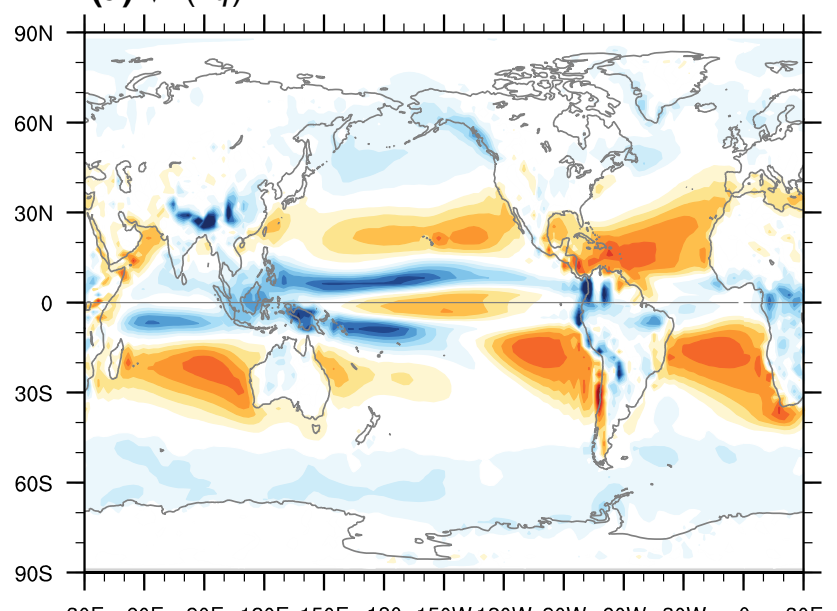

$30 \mathrm{E}$ 60E $90 \mathrm{E}$ 120E 150E 180 150W 120W 90W 60W 30W $0 \quad 30 \mathrm{E}$ (b) EMP

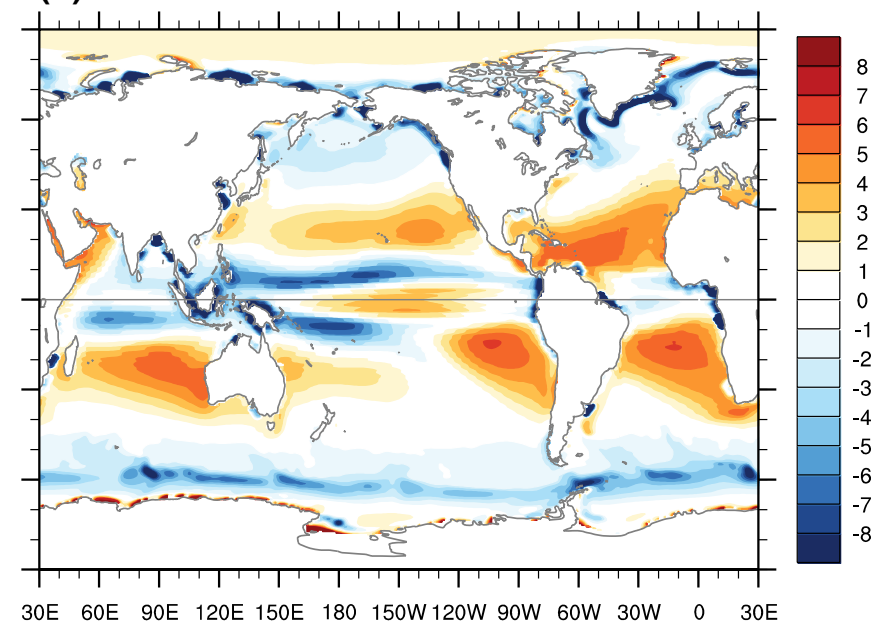

Fig. 10 The horizontal patterns of a the divergence of vertical integrated water vapor transport $\rho_{\mathrm{a}} \nabla \cdot(v q)$ and $\mathbf{b}$ the net fresh water loss $\rho_{\mathrm{a}}$ EMP over the global ocean (unit: $10^{-5} \mathrm{~kg} / \mathrm{m}^{2} / \mathrm{s}$ )

a brake for the poleward OHT carried by the thermal-driven meridional overturning circulation (Huang 2005). If there is no poleward fresh water transport by the atmosphere, the buoyancy driven meridional overturning circulation would be stronger. In other words, the $\mathrm{AHT}_{\mathrm{LE}}$ associated with water vapour cycle should be negatively correlated with the OHT, which should work better for the coupled system over the Atlantic where the fresh water forcing is one of key factors in determining the AMOC. Over the region of Indo-Pacific Ocean, the wind-driven STC dominates and the fresh water forcing plays the minor role.

The consistency between $\mathrm{AHT}_{\mathrm{LE}}$ and $\mathrm{HT}_{\mathrm{EMP}}$ suggests that the individual ocean contribution to the $\mathrm{AHT}_{\mathrm{LE}}$ can be quantified. It is reasonable to guess that the Indo-Pacific Ocean $\left(\mathrm{HT}_{\mathrm{EMP}}^{\mathrm{Pac}}\right.$ ) contributes to the $\mathrm{AHT}_{\mathrm{LE}}$ the most due to its area. Figure 11 shows the latent heat transport over different ocean basins. It is seen that the equatorward $\mathrm{AHT}_{\mathrm{LE}}$ in the tropical SH occurs exclusively over the Indo-Pacific, while that in the tropical NH occurs mainly over the Atlantic. Towards the higher latitudes, the Atlantic ( $\mathrm{HT}_{\mathrm{EMP}}^{\mathrm{Atl}}$ ) becomes more important. This is particularly clear over the ocean north of $40^{\circ} \mathrm{N}$. Although it has a zonal extension much smaller than the Pacific, the Atlantic provides the atmosphere more water vapour in the tropics (Fig. 10b), sustaining a poleward eddy LE transport in the extratropics that is stronger than the Pacific does (Fig. 11).

\subsection{Divergence of meridional heat transport}

The meridional heat transport in the climate system can be thus thought to be maintained by three components: the dry air heat transport $\mathrm{AHT}_{\mathrm{DSE}}$, the OHT and the joint mode $\mathrm{AHT}_{\mathrm{LE}}$ (Fig. 12a). The $\mathrm{AHT}_{\mathrm{DSE}}$ is still the largest

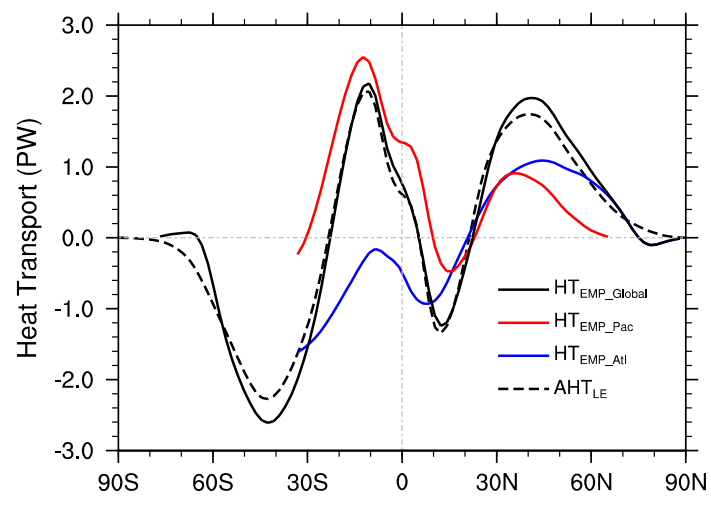

Fig. 11 The atmospheric LE transport obtained from the ocean surface EMP. The black, red and blue lines are for the global ocean $\left(\mathrm{HT}_{\mathrm{EMP}-\mathrm{global}}\right)$, the Indo-Pacific $\left(\mathrm{HT}_{\mathrm{EMP}-\mathrm{Pac}}\right)$ and the Atlantic $\left(\mathrm{HT}_{\mathrm{EMP}-\mathrm{Atl}}\right)$, respectively. The dashed black line shows the $\mathrm{AHT}_{\mathrm{LE}}$

component, but is not much larger than other components. The $\mathrm{AHT}_{\mathrm{LE}}$ and OHT are comparable, and both have the peak poleward transport of about $2 \mathrm{PW}$. However, for local climate, it is the divergence of the heat transport, not the heat transport itself that really matters (Huang 2005). In order to gain an insight into their relative importance to local climate, the meridional divergences of $\mathrm{AHT}_{\mathrm{DSE}}$, $\mathrm{HT}_{\mathrm{EMP}}$ and $\mathrm{OHT}$ are examined (Fig. 12b). The negative (positive) divergence of heat transport represents heat gain (loss) of the local climate. Here the divergence of $\mathrm{HT}_{\mathrm{EMP}}$ can be easily obtained by zonal integration of the EMP shown in Fig. 10b.

In the deep tropics $\left(20^{\circ} \mathrm{S}-20^{\circ} \mathrm{N}\right)$, the LE is the only heat source to the coupled system $\left(\mathrm{dHT}_{\mathrm{EMP}} / \mathrm{dy}<0\right)$, while the ocean and dry air $\left(\mathrm{dOHT} / \mathrm{dy}>0, \mathrm{dAHT}_{\mathrm{DSE}} / \mathrm{dy}>0\right.$ ) transport heat out of the tropics (Fig. 12a). The double 

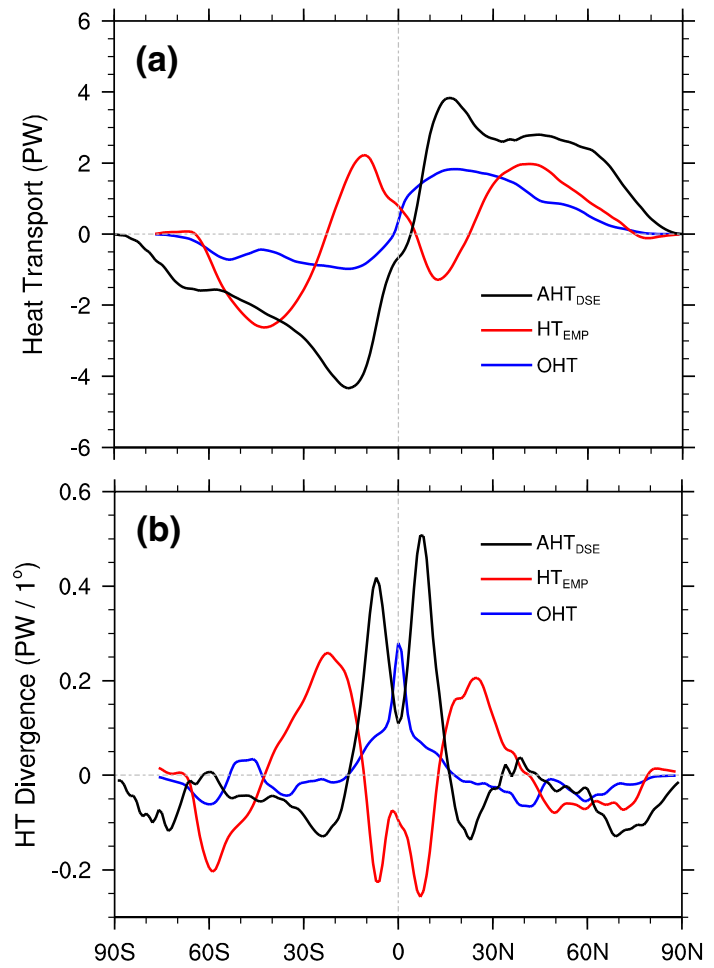

Fig. 12 a The atmosphere dry static energy transport $\mathrm{AHT}_{\mathrm{DSE}}$ (black), the latent energy transport $\mathrm{HT}_{\mathrm{EMP}}$ (red) and the total OHT (blue) and $\mathbf{b}$ their meridional divergences (unit: $\mathrm{PW} / 1^{\circ}$ )

peaks in the $\mathrm{HT}_{\mathrm{EMP}}$ and $\mathrm{AHT}_{\mathrm{DSE}}$ divergences correspond to the location of ITCZ, where the enormous LE convergence has to be balanced by dry air heat divergence. These heat convergences occur predominantly over the Indo-Pacific ocean (Figure not shown), because the ITCZ there is much stronger than that in the Atlantic (Fig. 10). In the ocean, the peak divergence occurs right on the equator, corresponding to the equatorial upwelling and poleward Ekman transport. In the subtropics of two hemispheres $\left(20-40^{\circ} \mathrm{N} / \mathrm{S}\right)$, the LE divergence becomes the only stabilizing factor to the local climate, while the dry air static energy convergence is the dominant heat source. In the higher latitudes, there are differences between the $\mathrm{NH}$ and the $\mathrm{SH}$. In the $\mathrm{NH}$ mid-latitudes $\left(40-50^{\circ} \mathrm{N}\right)$, the OHT convergence is the dominant heat source. Towards the higher latitudes, sequentially, the $\mathrm{HT}_{\mathrm{EMP}}$ convergence becomes dominant over $50-60^{\circ} \mathrm{N}$ and then the $\mathrm{AHT}_{\mathrm{DSE}}$ convergence dominates over the polar latitudes. These three components work like a relay team in determining the local climate at different latitude bands (Huang 2005). In the SH mid-high latitudes, the relay is completed only by two components. The $\mathrm{HT}_{\mathrm{EMP}}$ plays the remarkable role over $40-70^{\circ} \mathrm{S}$ and then the $\mathrm{AHT}_{\mathrm{DSE}}$ takes the role poleward of $70^{\circ} \mathrm{S}$. The reduced ocean role in the $\mathrm{SH}$ is due to the unidirectionally northward heat transport in the Atlantic.

\section{Summary and discussion}

Using a state-of-the-art coupled model, this work quantifies every individual component of the MHT in the climate system. We think it is crucial to examine the consistency between heat transports from direct and indirect approaches in a coupled system first, to build the credibility for the next step studies. There are several different ways to look at the MHT components. For the OHT, the contributions can be divided into by horizontal gyres and meridional overturning cells (This has been studied by many researchers and is not a focus in this work), or by warm cells and cold cells, or components by Euler mean circulation, mesoscale eddies, sub-meso scale eddies and dissipation. For the AHT, the contributions come from the dry air static energy and the water vapour energy. Both of them can be further decomposed into by the mean circulation and eddies.

This work identifies that the OHT due to mesoscale eddies and dissipation determines the poleward OHT in the SH mid-high latitudes. Unlike the poleward OHT in the NH that is predominantly carried out by the Euler mean current, the poleward OHT in the SH are fulfilled by the relay of the mean current, mesoscale eddies and dissipation. For the AHT components we emphasize that the LE transport plays the critical role in the Earth energy balance. One kilogram of water vapour can deliver $2.5 \times 10^{6} \mathrm{~J}$ of heat, but one kilogram of air (water) can only release $10^{4} \mathrm{~J}\left(4.18 \times 10^{4} \mathrm{~J}\right)$ of heat for a $10{ }^{\circ} \mathrm{C}$ cooling (Huang 2005). This makes the atmospheric LE transport significant in the climate system. For the first time this work quantifies the individual ocean contribution to the atmospheric LE transport, because the LE transport can be also precisely calculated from the EMP over the ocean. The Indo-Pacific contributes the most of the LE in the SH, while the Atlantic dominates the LE in the $\mathrm{NH}$, particularly in the tropics and $40^{\circ} \mathrm{N}$ poleward. The magnitude of basin contribution is mainly determined by the basin size. However, in the latitude band of $15-35^{\circ} \mathrm{N}$, although the Atlantic has zonal extension much smaller than the Pacific, the LH transports in the two basins are comparable due to much stronger EMP in the Atlantic.

This work focuses on the climatological mean state. The contributions of heat transport components are summarized in Fig. 13. The numbers in Fig. 13 indicate the rough percentage of the heat transport components in the global MHT. Different components play different role in different regions. In the Indo-Pacific the heat transport is fulfilled by wind-driven circulations. In the Atlantic the heat transport is carried by both wind-driven and thermohaline circulations. In the $\mathrm{NH}$ tropics they contribute nearly 40 and $20 \%$ of the total OHT, respectively. In the $\mathrm{NH}$ mid-high latitudes $\left(40-60^{\circ} \mathrm{N}\right)$, however, nearly $80 \%$ of the total OHT is carried by the Atlantic cold cells. For 
Fig. 13 A summary schematic diagram showing the contributions of heat transport to the total MHT in the Earth system. The number (unit: \%) in the parentheses indicates the percentage of the each component in the total MHT, which is obtained by comparing the maximum value of the component to the maximum total MHT (roughly $6 \mathrm{PW}$ )

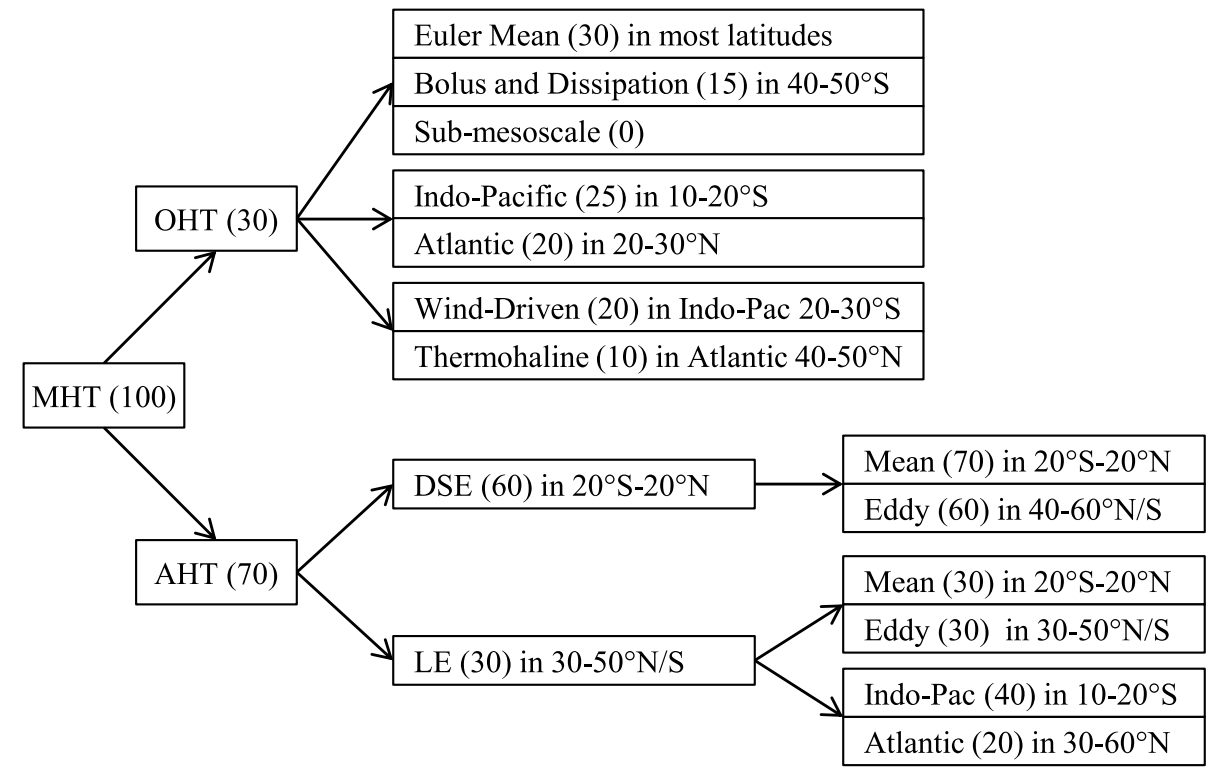

the atmosphere, the relative importance of the dry air and water vapour heat transports changes with latitudes. In the tropics $\left(20^{\circ} \mathrm{S}-20^{\circ} \mathrm{N}\right)$ the $\mathrm{LE}$ transport is equatorward and compensates partially the poleward DSE transport. In the extratropics, the LE and DSE are comparable in poleward transport, both of which are dominated by the eddy components. The eddy DSE transport is particularly important in the SH extratropics, which determines the poleward AHT there, reversing the equatorward mean DSE transport. A common feature in the OHT and AHT is that the eddy contribution, instead of mean circulation, dominates the MHT in the Southern Ocean region.

The contributions of warm and cold cells to the OHT are quantified for the first time in a coupled system in this work. The conclusions qualitatively agree with the work by Ferrari and Ferreira (2011) in an ocean-alone model. We emphasize that in the $\mathrm{SH}$ and the tropical $\mathrm{NH}$, the thermocline circulation (warm cells) dominates the OHT. The AMOC (cold cells) dominate the OHT in the mid-high latitudes Atlantic, with a more important role than that suggested in Ferrari and Ferreira (2011). We have not done sensitivity experiments to estimate the importance of abyssal mixing in the OHT. Here it seems reasonable to agree with Ferrari and Ferreira (2011) that the abyssal mixing below 2,000 $\mathrm{m}$ has little impact on the OHT (Fig. 6). This is an issue we intend to pursue in future work.

The MHT provides a mechanism of global scale climate interaction among different latitude bands. However, it is the divergence of MHT, instead of the MHT itself that really matters to the local climate change. In the deep tropics, the LE convergence is the only heat source to the coupled system, which occurs mainly over the Indo-Pacific
Ocean. In the subtropics of both hemispheres $\left(20-40^{\circ} \mathrm{N} /\right.$ $\mathrm{S})$, the DSE convergence is the dominant heat source. In the NH mid-high latitudes, the convergences of the OHT, the LE and the DSE become the dominant heat source sequentially. These three components work like a relay team in determining the local climate at different latitude bands. In the SH mid-high latitudes, the relay is completed only by the LE and DSE convergences. The reduced role of OHT in the SH is due to the northward heat transport in the Atlantic. Exploring the MHT and its divergence is equivalent to link the local climate change to the global scale climate.

This is a benchmark work for our next step study on the low frequency variability in the MHT. The precise calculation of the AHT and OHT is the key initial step to correctly assess the natural variability as well as the anthropogenic change of the heat transport. Particularly it is critical to calculate the AHT and OHT independently when studying the relationship between their changes, such like the so-called "Bjerknes compensation” (Bjerknes 1964; Czaja and Marshall 2006; Shaffrey and Sutton 2006; Vellinga and $\mathrm{Wu}$ 2008), which suggests an important constraint in the Earth's climate change, or in other words, a mechanism to maintain the stability of the Earth's climate. The MHT and its changes are closely related to the pattern, magnitude and variation of atmosphere and ocean circulations. Therefore, it provides an entry to study various aspects of the climate change extensively, including the planetary scale atmosphere-ocean feedback processes. In addition, knowing the MHT components and their changes will greatly help us to understand the fundamentals of the climate change. These are our works in the near future. 
Acknowledgments We are grateful to Profs. Z. Liu and R. Huang for invaluable suggestions and discussions. This work is jointly supported by the NSF of China (Nos. 40976007, 41176002, 41376007), the National Basic Research Program of China (No. 2012CB955200), the Special Fund for Meteorological Scientific Research in the Public Interest of CMA (No. GYHY201006022) and the Norwegian Research Council through the East Asian DecCen project (No. 193690/S30). All the experiments are performed on the supercomputer at the LaCOAS, Peking University.

Open Access This article is distributed under the terms of the Creative Commons Attribution License which permits any use, distribution, and reproduction in any medium, provided the original author(s) and the source are credited.

\section{Appendix}

\section{Oceanic heat transport}

The ocean potential temperature equation can be briefly written as

$$
\begin{aligned}
\frac{\partial \theta}{\partial t} & +\frac{\partial\left(u+u^{*}\right) \theta}{\partial x}+\frac{\partial\left(v+v^{*}\right) \theta}{\partial y}+\frac{\partial\left(w+w^{*}\right) \theta}{\partial z} \\
& =R(\theta)+\frac{\partial Q}{\partial z} .
\end{aligned}
$$

Here we have used $\nabla_{3} \cdot \boldsymbol{V}=0$ and $\nabla_{3} \cdot \boldsymbol{V}^{*}=0$, where $\boldsymbol{V}=(u, v, w)$ and $\boldsymbol{V}^{*}=\left(u^{*}, v^{*}, w^{*}\right) . \boldsymbol{V}$ is the Euler mean velocity and $V^{*}$ is the bolus velocities induced by mesoscale eddies. $Q$ is the heat source from the top. $R(\theta)$ represents the Redi isoneutral diffusion term for small slope (Redi 1982). In CESM POP2 (Smith et al. 2010), the bolus velocities is parameterized by Gent-McWilliams scheme (Gent and McWilliams 1990),

$u^{*}=\left(v \frac{\rho_{x}}{\rho_{z}}\right)_{z}, \quad v^{*}=\left(v \frac{\rho_{y}}{\rho_{z}}\right)_{z}, \quad w^{*}=-\nabla \cdot\left(v \frac{\nabla \rho}{\rho_{z}}\right)$,

where $v$ is a thickness diffusivity and subscripts $x, y, z$ on $\rho$ denote partial derivatives with respect to those variables. The gradient or divergence operator $\nabla$ is two-dimensional, $\nabla=\left(\frac{\partial}{\partial x}, \frac{\partial}{\partial y}\right)$.

Integrating Eq. (1) definitely along $x$ and $z$ and indefinitely along $y$ with periodic boundary conditions in $x$, and $w=0, \frac{\partial \theta}{\partial z}=0$ at the ocean top and bottom, we have

$$
\begin{gathered}
\iiint \frac{\partial \theta}{\partial t} d x d y d z+\iint\left(v+v^{*}\right) \theta d x d z \\
=\iiint R(\theta) d x d y d z+\iint Q_{0} d x d y
\end{gathered}
$$

where $Q_{0}$ is the net heat flux at the surface.

Equation (3) is the equation for OHT, which includes the OHT deduced indirectly from the net surface heat flux, the OHTs calculated directly from the Euler mean circulation, bolus circulation as well as the diffusion and the change in the ocean heat content. They are given as follows,
$O H T_{H F}=\iint Q_{0} d x d y$

$O H T_{E u l}=\iint v \theta d x d z$

$O H T_{B o l}=\iint v^{*} \theta d x d z=\iint\left(v \frac{\rho_{y}}{\rho_{z}}\right)_{z} \theta d x d z$,

$O H T_{\text {Diff }}=-\iiint R(\theta) d x d y d z$

$O H T_{H C}=\iiint \frac{\partial \theta}{\partial t} d x d y d z$.

Therefore, Eq. (3) can be rewritten as.

$O H T_{H F}=O H T_{H C}+O H T_{E u l}+O H T_{B o l}+O H T_{\text {Diff }}$.

Note that in (4)-(8) all the integrals along $y$ are indefinite integral. The sea water specific heat $c_{p}$ and the density $\rho_{0}$ are assumed to be constants and should be put in the formulas when doing the calculation. The indirect method calculating the OHT from the net surface heat flux is widely used in previous studies, in estimating the OHT from observation and reanalysis data (e.g., Carissimo et al. 1985; Trenberth and Solomon 1994). The $O H T_{D I F F}$ and the $O H T_{H C}$ are highly depending on the locations and timescale concerned. Generally, the $O H T_{D I F F}$ could not be omitted where the meridional temperature gradient is strong, like the Antarctic Circumpolar Circulation (ACC) region and the extension of Gulf Stream and Kuroshio Current; the $O H T_{H C}$ could not be neglected when short timescales, like annual or interannual, are considered.

The effect of submeso-scale eddies $(\sim 1 \mathrm{~km})$, in particular the restratifying effect on the mixed layer, is represented by the FFH parameterization in CESM POP2 (Fox-Kemper et al. 2008, 2011; Fox-Kemper and Ferrari 2008), which is given by

$\boldsymbol{\Psi}^{\prime}=C_{e} \frac{H^{2} \nabla \bar{b}^{z} \times \hat{z}}{|f|} \mu(z)$,

$\mu(z)=\max \left\{0,\left[1-\left(\frac{2 z}{H}+1\right)^{2}\right]\left[1+\frac{5}{21}\left(\frac{2 z}{H}+1\right)^{2}\right]\right\}$,

where $b \equiv g\left(\rho_{0}-\rho\right) / \rho_{0}$ is the reduced gravity or the buoyancy, $H$ is mixed layer depth, $f$ is the Coriolis parameter, and $\hat{z}$ is the unit vertical vector. The overbar with subscript $z$ on $\nabla \bar{b}^{z}$ is understood to be the depth-average of $\nabla \bar{b}$ over the mixed layer. The efficiency coefficient $C_{e}$ is approximately 
0.06 (Fox-Kemper and Ferrari 2008). Note that the parameterization is only non-zero within the mixed layer.

The submeso-scale eddy-induced velocity field is then given by

$\mathbf{u}^{\prime}=\nabla \times \Psi^{\prime}$,

and the contribution of these mixed layer eddies to the meridional heat transport is

$O H T_{S u b}=\iint v^{\prime} \theta d x d z$.

Therefore, the total OHT that can be directly calculated from the ocean velocity and thermal fields is

$O H T_{V T}=O H T_{A d v}+O H T_{D i f f}$,

Here the total advective $O H T_{A d v}$ includes the contributions of Euler mean, meso-scale and submeso-scale circulations,

$O H T_{A d v}=O H T_{E u l}+O H T_{B o l}+O H T_{S u b}$.

If neglecting the meso-scale, submeso-scale processes and diffusion, the ocean heat transport is approximated by the Euler mean circulation. For a steady climate, in principle, the $O H T_{E u l}$ should be equivalent to the OHT indirectly deduced from the ocean net surface heat flux, that is,

$O H T_{H F} \approx O H T_{E u l}$.

The validity of $O H T_{V T}$ depends entirely on the validity of the ocean circulation scheme. Great care should be taken when calculating OHT directly. One should always check the conservation of mass before doing further calculation. That is to keep

$\int_{0}^{2 \pi} d \lambda \int_{-D}^{0} v \cos \varphi d z=0$

Factors that are not taken into consideration here like evaporation and precipitation may affect the validity of Eq. (17). But their effects are rather small. Usually this condition will be forced to hold in the numerical model. Non-conservation of mass may also arise during the postprocessing procedure of model outputs. For example, regridding model data using non-conservative remapping methods like bilinear interpolation will break the conservation of mass, and thus leading to spurious OHTs.

\section{Oceanic heat function}

Follow Ferrari and Ferreira (2011), we calculated the heat function. The basic idea in the concept of heat function is that the OHT by ocean flows can be expressed in terms of the mass transport in temperature layers. By introducing the streamfunction $\Psi(y, \theta)$, which represents the total horizontal mass transport below a $\theta$-surface, the heat function is then defined as follow,
$H(y, \theta) \equiv \rho_{0} c_{p} \int_{\theta_{B}(y)}^{\theta(y)} \Psi(y, \theta) d \theta$,

where $\theta_{B}(y)$ is the potential temperature of sea waters at the ocean bottom. The heat function $H(y, \theta)$ represents the northward heat transport across a latitude $\mathrm{y}$ and below a temperature $\theta$, associated with the streamfunction $\Psi(y, \theta)$.

The OHT by individual branches of circulation can be given by

$\operatorname{OHT}\left(y, \theta_{u}, \theta_{l}\right)=\rho_{0} c_{p} \int_{\theta_{u}(y)}^{\theta_{l}(y)}\left(\Psi(y, \theta)-\Psi\left(y, \theta_{l}\right)\right) d \theta$.

The temperature $\theta_{u}$ and $\theta_{l}$ are the maximum and minimum temperature reached by a close circulation at a latitude $y$. $\Psi(y, \theta)-\Psi\left(y, \theta_{l}\right)$ is the meridional mass transport between $\theta$ and $\theta_{l}$.One can refer to Ferrari and Ferreira (2011) for more details. In this paper, we use (19) to estimate the OHT by the warm, cold and mixed cells in the CESM.

\section{Atmospheric heat transport}

The AHT is usually deduced indirectly from the net heat flux gained by the atmosphere, which is the difference of the net heat flux between the top of atmosphere (TOA, $F_{t}$ ) and the surface $F_{\mathrm{s}}$ :

$A H T_{H F}=\int_{\pi / 2}^{\varphi} d \varphi \int_{0}^{2 \pi}\left(F_{t}-F_{s}\right) a_{e}^{2} \cos \varphi d \lambda$.

The AHT can be also calculated directly from the atmosphere MSE, similar to the calculation of $O H T_{A d v}$. Here the integration is along the pressure coordinate:

$A H T_{V T}=\int_{0}^{2 \pi} d \lambda \int_{p_{t}}^{p_{s}} a_{e} v h \cos \varphi / g d p$

in which the MSE is given by:

$h \equiv c_{p a} \theta_{a} \equiv c_{p a} T+l_{v} q+g z$.

$c_{p a}, l_{v}$ are the specific heat capacity of dry air and the latent heat of vaporization. $T, q$ and $g z$ are the temperature, specific humidity and the potential energy. The quantity $\theta_{a}$ is proportional to the MSE. It is a measure of enthalpy rather than entropy and can be treated as, but not the exactly same as, moist potential temperature (Czaja and Marshall 2006). In our calculation we separate the MSE into the DSE and LH, so Eq. (22) can be rewritten as,

$h=c_{p a} \theta+l_{v} q$,

where $\theta$ is the dry potential temperature of the atmosphere. Thus the AHT can be decomposed into contributions from dry air $\left(A H T_{D S E}\right)$ and water vapor $\left(A H T_{L E}\right)$ : 
$A H T_{D S E}=\int_{0}^{2 \pi} d \lambda \int_{p_{t}}^{p_{s}} a_{e} c_{p a} v \theta \cos \varphi / g d p$

$A H T_{L E}=\int_{0}^{2 \pi} d \lambda \int_{p_{t}}^{p_{s}} a_{e} l_{v} v q \cos \varphi / g d p$

Besides, the AHT can be also decomposed into contributions from the mean flow $\left(A H T_{M E A N}\right)$ and eddies $\left(A H T_{E D D Y}\right)$ :

$$
\begin{aligned}
A H T_{M E A N}= & \int_{0}^{2 \pi} d \lambda \int_{p_{t}}^{p_{s}} a_{e} c_{p a} \bar{v} \bar{\theta} \cos \varphi / g d p \\
& +\int_{0}^{2 \pi} d \lambda \int_{p_{t}}^{p_{s}} a_{e} l_{v} \overline{v q} \cos \varphi / g d p \\
A H T_{E D D Y}= & \int_{0}^{2 \pi} d \lambda \int_{p_{t}}^{p_{s}} a_{e} c_{p a} v \theta \cos \varphi / g d p \\
& +\int_{0}^{2 \pi} d \lambda \int_{p_{t}}^{p_{s}} a_{e} l_{v} v q \cos \varphi / g d p-A H T_{M E A N},
\end{aligned}
$$

where $\overline{()}$ means monthly averaged.

In CESM, the model outputs include $v \theta$ and $v q$. Using monthly outputs, the $\bar{v} \bar{\theta}$ and $\overline{v q}$ can be easily calculated. The eddy transport can be then obtained by subtracting the mean transport from the total, that is, $\overline{v^{\prime} \theta^{\prime}}=\overline{v \theta}-\bar{v} \bar{\theta}, \overline{v^{\prime} q^{\prime}}=$ $\overline{v q}-\overline{v q}$. Here the eddy transport includes the contributions from both the stationary waves and transient eddies. Therefore the AHT consists of four components,

$$
\begin{aligned}
A H T_{V T}= & A H T_{D S E}+A H T_{L E}=A H T_{M D S E}+A H T_{E D S E} \\
& +A H T_{M L E}+A H T_{E L E},
\end{aligned}
$$

which is called as the mean dry static energy (MDSE), the eddy dry static energy (EDSE), the mean latent energy (MLE) and the eddy latent heat (ELE), respectively.

The CESM CAM5 uses $\sigma-p$ coordinate in the vertical. Our calculations are on the $p$-coordinate. The spurious non-conservation of mass will also arise when interpolating data from $\sigma-p$-coordinate to $p$-coordinate in this method. That is

$$
\int_{0}^{2 \pi} d \lambda \int_{p_{t}}^{p_{s}} a_{e} v \cos \varphi / g d p \neq 0
$$

We use the spurious mass transport (29) to derive the spurious meridional velocity $v^{+}$and update the original meridional velocity $v$ with $v-v^{+}$. That is,

$$
v^{+}=\int_{0}^{2 \pi} d \lambda \int_{p_{t}}^{p_{s}} a_{e} v \cos \varphi / g d p / \int_{0}^{2 \pi} d \lambda \int_{p_{t}}^{p_{s}} a_{e} \cos \varphi / g d p,
$$

$v^{*}=v-v^{+}$.

Substituting $v$ with $v^{*}$ in (21)-(27), the recalculated $A H T_{V T}$ is well consistent with the $A H T_{H F}$ in the CESM, that is,

$A H T_{V T} \approx A H T_{H F}$.

In a coupled climate system (32) should be well-established. This is one of strong constraints that can be used to validate coupled models. The CESM1.0 is validated.

\section{References}

Bjerknes J (1964) Atlantic air-sea interaction. Adv Geophys 10:1-82 Boccaletti G, Ferrari R, Adcroft A, Ferreira D, Marshall JC (2005) The vertical structure of ocean heat transport. Geophys Res Lett 32(L10603):1-4

Bryan R, Oort AH (1984) Seasonal variation of the global water balance based on aerological data. J Geophys Res 89:11711-11730

Carissimo BC, Oort AH, Vonder Haar TH (1985) Estimating the meridional energy transports in the atmosphere and ocean. J Phys Oceanogr 15:82-91

Czaja A, Marshall J (2006) The partitioning of poleward heat transport between the atmosphere and ocean. J Atmos Sci 63:1498-1511

Danabasoglu G, Marshall J (2007) Effects of vertical variations of thickness diffusivity in an ocean general circulation model. Ocean Model 18:122-141. doi:10.1016/j.ocemod.2007.03.006

Danabasoglu G, Bates S, Briegleb BP, Jayne SR, Jochum M, Large WG, Peacock S, Yeager SG (2012) The CCSM4 ocean component. J Clim 25:1361-1389. doi:10.1175/JCLI-D-11-00091.1

Döös K, Webb D (1994) The Deacon cell and the other meridional cells of the southern ocean. J Phys Oceanogr 24:429-442

Farneti R, Gent PR (2011) The effects of the eddy-induced advection coefficient in a coarse-resolution coupled climate model. Ocean Model 39:135-145. doi:10.1016/j.ocemod.2011.02.005

Farneti R, Vallis GK (2013) Meridional energy transport in the coupled atmosphere-ocean system: compensation and partitioning. J Clim 26:7151-7166. doi:10.1175/JCLI-D-12-00133.1

Ferrari R, Ferreira D (2011) What processes drive the ocean heat transport? Ocean Model 38:171-186. doi:10.1016/j.ocemod.2011.02.013

Fox-Kemper B, Ferrari R (2008) Parameterization of mixed layer eddies. Part II: prognosis and impact. J Phys Oceanogr 38:1166-1179

Fox-Kemper B, Ferrari R, Hallberg RW (2008) Parameterization of mixed layer eddies. Part I: theory and diagnosis. J Phys Oceanogr 38:1145-1165

Fox-Kemper B, Danabasoglu G, Ferrari R, Gries SM, Hallberg RW, Holland MM, Maltrud ME, Peacock S, Samuels BL (2011) Parameterization of mixed layer eddies. III: implementation and impact in global ocean climate simulations. Ocean Model 39:61-78

Gent P, McWilliams J (1990) Isopycnal mixing in ocean circulation models. J Phys Oceanogr 20:150-155

Goldsbrough GR (1933) Ocean currents produced by evaporation and precipitation. Proc R Soc Lond Ser A 141:241-248

Greatbatch RJ, Zhai X (2007) The generalized heat function. Geophys Res Lett 34:L21601

Held IM (2001) The partitioning of the poleward energy transport between the tropical ocean and atmosphere. J Atmos Sci 58:943-948

Huang R (2005) Contribution of oceanic circulation to the poleward heat flux. J Ocean Univ China 4:277-287

Hunke E, Lipscomb W (2008) CICE: The Los Alamos Sea Ice Model, documentation and software user's manual, version 4.0. Tech. Rep. LA-CC-06-012, Los Alamos National Laboratory 
Jayne SR, Marotzke J (2002) The oceanic eddy heat transport. J Phys Oceanogr 32:3328-3345

Lawrence DM, Oleson KW, Flanner MG, Fletcher CG, Lawrence PJ, Levis S, Swenson SC, Bonan GB (2012) The CCSM4 land simulation, 1850-2005: assessment of surface climate and new capabilities. J Clim 25:2240-2260. doi:10.1175/JCLI-D-11-00103.1

Long MC, Lindsay K, Peacock S, Moore JK, Doney SC (2013) Twentieth-century oceanic carbon uptake and storage in CESM1 (BGC). J Clim 26. doi:10.1175/JCLI-D-12-00184.1

Marshall J, Radko T (2003) Residual-mean solutions for the antarctic circumpolar current and its associated overturning circulation. $\mathrm{J}$ Phys Oceanogr 33:2341-2354

Marshall J, Ferreira D, Campin J-M, Enderton D (2007) Mean climate and variability of the atmosphere and ocean on an aquaplanet. J Atmos Sci 64:4270-4286

Marshall J, Donohoe A, Ferreira D, McGee D (2013) The ocean's role in setting the mean position of the Inter-Tropical Convergence Zone. Clim Dyn. doi:10.1007/s00382-013-1767-z

Masuda K (1988) Meridional heat transport by the atmosphere and the ocean; analysis of FGGE data. Tellus 40A:285-302

Meehl GA, Washington WM, Arblaster JM, Hu A, Teng H, Kay JE, Gettelman A, Lawrence DM, Sanderson BM, Strand WG (2013) Climate change projections in CESM1 (CAM5) compared to CCSM4. J Clim. doi:10.1175/JCLI-D-12-00572.1

Michaud R, Derome J (1991) On the mean meridional transport of energy in the atmosphere and oceans as derived from six years of ECMWF analyses. Tellus 43A:1-14

Neale RB et al (2010) Description of the NCAR community atmosphere model (CAM5.0), Tech. Rep. NCAR/TN-486 + STR, National Center for Atmospheric Research, Boulder, CO, USA

Neale R, Richter J, Park S, Lauritzen P, Vavrus S, Rasch P, Zhang M (2013) The mean climate of the Community Atmosphere Model (CAM4) in forced SST and fully coupled experiments. J Clim 26:5150-5168. doi:10.1175/JCLI-D-12-00236.1

Oort AH, Vonder Haar TH (1976) On the observed annual cycle in the ocean-atmosphere heat balance over the Northern Hemisphere. J Phys Oceanogr 6:781-800

Redi MH (1982) Oceanic isopycnal mixing by coordinate rotation. J Phys Oceanogr 12:1154-1158
Savijärvi HI (1988) Global energy and moisture budgets from rawinsonde data. Mon Weather Rev 116:417-430

Schmitt RW, Bogden PS, Dorman CE (1989) Evaporation minus precipitation and density fluxes for the North Atlantic. J Phys Oceanogr 19:1208-1221

Shaffrey L, Sutton R (2006) Bjerknes compensation and the decadal variability of the energy transports in a coupled climate model. J Clim 19:1167-1181

Smith RD et al (2010) The Parallel Ocean Program (POP) reference manual. Tech. Rep. LAUR-10-01853, Los Alamos National Laboratory

Treguier AM, England MH, Rintoul SR, Madec G, Le Sommer J, Molines J-M (2007) Southern ocean overturning across streamlines in an eddying simulation of the Antarctic Circumpolar Current. Ocean Sci 3:491-507

Trenberth KE (1979) Mean annual poleward energy transports by the oceans in the Southern Hemisphere. Dyn Atmos Oceans 4:57-64

Trenberth KE, Caron JM (2001) Estimates of meridional atmosphere and ocean heat transports. J Clim 14:3433-3443

Trenberth KE, Solomon A (1994) The global heat balance: heat transports in the atmosphere and ocean. Clim Dyn 10:107-134

Trenberth KE, Stepaniak DP (2003a) Covariability of components of poleward atmospheric energy transports in seasonal and interannual timescales. J Clim 16:3691-3705

Trenberth KE, Stepaniak DP (2003b) Seamless poleward atmospheric energy transports and implications for Hadley circulation. J Clim 16:3705-3722

Vallis GK, Farneti R (2009) Meridional energy transport in the coupled atmosphere-ocean system: scaling and numerical experiments. Q J R Meteorol Soc 135:1643-1660

Vellinga M, Wu P (2008) Relations between northward ocean and atmosphere energy transports in a coupled climate model. J Clim 21:561-575

Vonder Haar TH, Oort AH (1973) A new estimate of annual poleward energy transport by the oceans. J Phys Oceanogr 3:169-172

Wunsch C (2005) The total meridional heat flux and its oceanic and atmosphere partition. J Clim 18:4374-4380 